\title{
In vitro activity of pomegranate peel extract alone and in electrospun poly(vinyl alcohol)/sodium alginate matrix
}

\author{
Atividade in vitro de extrato de casca de romã sozinho e em matriz de poli(álcool vinílico)/alginato \\ de sódio preparada por eletrofiação.
}

\author{
Sanderson Vieira Batista ${ }^{1}$, Thais Martins da Silva ${ }^{2}$, Sthefany Brito Salomão ${ }^{1}$, Kamila Arêas Bastos ${ }^{1}$, Sarah \\ Oliveira Lamas de Souza ${ }^{3}$, Monique Alvarenga Pinto Cotrim ${ }^{3}$, Rodrigo Lambert Oréfice ${ }^{3}$, Sérgio Faloni de \\ Andrade $^{4}$, Francisco de Paula Careta ${ }^{1}$, Juliana Aparecida Severi ${ }^{1}$, Juliana Alves Resende ${ }^{1,2}$, Janaina Cecília \\ Oliveira Villanova ${ }^{1,2^{*}}$
}

\begin{abstract}
'Universidade Federal do Espírito Santo - UFES, Laboratório de Produção Farmacêutica, Alegre - ES, Brasil; ${ }^{2}$ Universidade Federal do Espírito Santo - UFES, Programa de Pós-graduação em Ciências Veterinárias, Alegre - ES, Brasil; ${ }^{3}$ Universidade Federal de Minas Gerais - UFMG, Laboratório de Engenharia de Polímeros e Compósitos, Belo Horizonte - MG, Brasil; ${ }^{4}$ Universidade Lusófona - CBIOS - Research Center for Biosciences and Health Technologies, Lisboa, Portugal

*corresponding author: pharmacotecnica@yahoo.com.br
\end{abstract}

\begin{abstract}
Wound dressings can support healing by acting as physical barriers and drug delivery systems. The present study aimed to evaluate the biological activity of films containing pomegranate peel extract at $1.25 \% \mathrm{w} / \mathrm{w}$ prepared by the electrospinning technique for use as wound dressing. The extract was subjected to an in vitro cytotoxicity assay using fibroblasts. The formation of fibers was confirmed using scanning electron microscopy. Biocompatibility was analyzed by determining the hemolysis index, while the susceptibility of bacterial strains and a fungus was investigated using the disc diffusion method. The extract proved to be nontoxic with cell proliferation occurring at a concentration $>30$ $\mu \mathrm{g} \cdot \mathrm{mL}^{-1}$. Photomicrograph images confirmed the formation of nanofibers. Films without or with the extract showed good hemocompatibility. The antimicrobial activity of films loaded with extract was demonstrated by the formation of zones of inhibition of Staphylococcus aureus, Staphylococcus epidermidis, and Candida albicans, suggesting that the release of the extract in the medium occurred at an adequate concentration to inhibit the proliferation of microorganisms. No zone of inhibition was observed for Escherichia coli. These results suggest that the film produced by electrospinning containing $1.25 \% \mathrm{w} / \mathrm{w}$ of the extract might serve as a bioactive wound dressing.
\end{abstract}

Keywords: Punica granatum, electrospinning, wound dressing, antimicrobial activity

\begin{abstract}
Resumo
Coberturas bioativas favorecem a cicatrização porque atuam como barreiras e sistemas de liberação de fármacos. O objetivo do presente estudo foi avaliar a atividade biológica de filmes contendo extrato de casca de romã a 1,25\% p/p, preparados pela técnica de eletrofiação, visando seu uso como cobertura bioativa. O extrato foi submetido a ensaio de citotoxicidade in vitro utilizando linhagem de fibroblastos. A formação das fibras foi confirmada por microscopia eletrônica de varredura. A biocompatibilidade foi analisada pela determinação do índice de hemólise enquanto a suscetibilidade de cepas de bactérias Gram-positivas, Gram-negativa e um fungo, foi investigada pelo método de disco-difusão. O extrato se mostrou atóxico, com proliferação celular ocorrendo em concentração $>30 \mu \mathrm{g} \cdot \mathrm{mL}^{-1}$. Fotomicrografias confirmaram a formação das nanofibras. Filmes sem ou com o extrato apresentaram boa hemocompatibilidade. A atividade antimicrobiana dos filmes contendo extrato foi comprovada pela formação de zonas de inibição para Staphylococcus aureus, Staphylococcus epidermidis e Candida albicans, sugerindo que a liberação do extrato no meio ocorreu em concentração adequada para inibir a proliferação dos microrganismos. Nenhuma zona de inibição foi observada para Escherichia coli. Tais resultados sugerem que o filme produzido por eletrofiação contendo $1,25 \% \mathrm{p} / \mathrm{p}$ do extrato se mostrou promissor para uso como cobertura bioativa.
\end{abstract}

Palavras-chave: Punica granatum, eletrofiação, cobertura bioativa, atividade aoutntimicrobiana 


\section{Introduction}

The constant advances in material sciences and pharmaceutical technology have permitted the development of coverings or wound dressings with differentiated functions, including the use as a reservoir for synthetic drugs, bioactive compounds, or biological factors that induce tissue regeneration and healing (1$3)$.

Historically, dressings were designed to be used as barriers to protect exposed areas of the skin or mucosa after a physical (e.g., due to an accident or surgical procedure), thermal, or chemical injury, or caused by a pathological condition $(1,2)$. Currently, different types of dressings are commercially available. Traditional dressings act as a passive barrier and are only intended to cover the wound and protect it against microbial contamination. They are similar to a gauze as both are designed to be in contact with the wound and are different from a bandage that holds the dressing in place (3). A semi-permeable dressing can alter the physiology of the wound micro-region, keep it moist, and promote healing. Semi-permeable dressings are presented as foams, films, hydrocolloids, and polymeric hydrogels (3). Another type of wound dressing currently under investigation is the bioactive wound dressing. In addition to functioning as a physical barrier, these dressings act as drug-delivery systems, containing therapeutic agents that may accelerate wound-tissue regeneration $(3,5)$, and are, in general, biocompatible, biodegradable, and non-toxic (3). There are several advantages of bioactive coverings used as in film form as compared to other types of wound dressings and conventional drug dosage forms. These bioactive coverings protect lesions against the entry of microorganisms that could trigger opportunistic infections; allow gaseous exchange between the injured tissue and the environment and maintain adequate humidity for tissue regeneration; release therapeutic agents locally at the injury site without the need for additional products, facilitate injury management; contribute to patient comfort, and reduce the time and cost of treatment (5-7).

\section{Introdução}

Os constantes avanços nas áreas de ciências dos materiais e da tecnologia farmacêutica permitem o desenvolvimento de curativos, também chamados coberturas ou wound dressings, com funções diferenciadas, incluindo o uso como reservatório de fármacos sintéticos, compostos bioativos ou fatores biológicos que induzem a regeneração e a cicatrização tecidual (1-3).

Historicamente, os curativos foram projetados para serem usados como barreiras, visando proteger áreas expostas da pele ou mucosa após ocorrência de lesão causada por trauma físico (por exemplo, devido a um acidente ou procedimento cirúrgico), térmico, químico ou por uma patologia $(1,2)$. Hoje, diferentes tipos de curativos estão disponíveis comercialmente. Coberturas tradicionais atuam como produtos passivos e se destinam apenas a recobrir a ferida, agindo como barreira física para proteção contra contaminação externa. São semelhantes a uma gaze: são projetadas para entrar em contato com a ferida e recobri-la, ao contrário de uma bandagem, que só mantém a cobertura fixa no lugar (3). Coberturas semi-permeáveis são capazes de alterar a fisiologia na microrregião das feridas, mantendoas úmidas e promovendo a regeneração tecidual. Estas se apresentam na forma de espumas, filmes, hidrocolóides e hidrogéis poliméricos (3). Outro tipo de cobertura investigada na atualidade é dita bioativa. Além de atuar como barreira física, a cobertura bioativa funciona como sistema de liberação de fármacos e pode conter diferentes agentes terapêuticos que favorecem o tratamento de feridas e aceleram a regeneração tecidual $(3,5)$. Coberturas bioativas são, em geral, biocompatíveis, biodegradáveis e não tóxicas (3). As coberturas bioativas utilizadas na forma de filme apresentam inúmeras vantagens quando comparadas à outros tipos de wound dressings e formas farmacêuticas convencionais. As coberturas bioativas protegem as lesões contra a entrada de microrganismos que podem desencadear infecções oportunistas; permitem trocas gasosas entre o tecido lesionado e o meio ambiente, proporcionando a manutenção de umidade adequada para a regeneração do tecido; liberam o agente terapêutico no local, sem a necessidade de aplicar mais de um tipo de produto; facilitam o manejo das lesões; contribuem para o conforto do paciente; e, reduzem o tempo e, consequentemente, os custos do tratamento (5-7). 


\section{Introduction}

The constant advances in material sciences and pharmaceutical technology have permitted the development of coverings or wound dressings with differentiated functions, including the use as a reservoir for synthetic drugs, bioactive compounds, or biological factors that induce tissue regeneration and healing (1$3)$.

Historically, dressings were designed to be used as barriers to protect exposed areas of the skin or mucosa after a physical (e.g., due to an accident or surgical procedure), thermal, or chemical injury, or caused by a pathological condition $(1,2)$. Currently, different types of dressings are commercially available. Traditional dressings act as a passive barrier and are only intended to cover the wound and protect it against microbial contamination. They are similar to a gauze as both are designed to be in contact with the wound and are different from a bandage that holds the dressing in place (3). A semi-permeable dressing can alter the physiology of the wound micro-region, keep it moist, and promote healing. Semi-permeable dressings are presented as foams, films, hydrocolloids, and polymeric hydrogels (3). Another type of wound dressing currently under investigation is the bioactive wound dressing. In addition to functioning as a physical barrier, these dressings act as drug-delivery systems, containing therapeutic agents that may accelerate wound-tissue regeneration $(3,5)$, and are, in general, biocompatible, biodegradable, and non-toxic (3). There are several advantages of bioactive coverings used as in film form as compared to other types of wound dressings and conventional drug dosage forms. These bioactive coverings protect lesions against the entry of microorganisms that could trigger opportunistic infections; allow gaseous exchange between the injured tissue and the environment and maintain adequate humidity for tissue regeneration; release therapeutic agents locally at the injury site without the need for additional products, facilitate injury management; contribute to patient comfort, and reduce the time and cost of treatment (5-7).

\section{Introdução}

Os constantes avanços nas áreas de ciências dos materiais e da tecnologia farmacêutica permitem o desenvolvimento de curativos, também chamados coberturas ou wound dressings, com funções diferenciadas, incluindo o uso como reservatório de fármacos sintéticos, compostos bioativos ou fatores biológicos que induzem a regeneração e a cicatrização tecidual (1-3).

Historicamente, os curativos foram projetados para serem usados como barreiras, visando proteger áreas expostas da pele ou mucosa após ocorrência de lesão causada por trauma físico (por exemplo, devido a um acidente ou procedimento cirúrgico), térmico, químico ou por uma patologia $(1,2)$. Hoje, diferentes tipos de curativos estão disponíveis comercialmente. Coberturas tradicionais atuam como produtos passivos e se destinam apenas a recobrir a ferida, agindo como barreira física para proteção contra contaminação externa. São semelhantes a uma gaze: são projetadas para entrar em contato com a ferida e recobri-la, ao contrário de uma bandagem, que só mantém a cobertura fixa no lugar (3). Coberturas semi-permeáveis são capazes de alterar a fisiologia na microrregião das feridas, mantendoas úmidas e promovendo a regeneração tecidual. Estas se apresentam na forma de espumas, filmes, hidrocolóides e hidrogéis poliméricos (3). Outro tipo de cobertura investigada na atualidade é dita bioativa. Além de atuar como barreira física, a cobertura bioativa funciona como sistema de liberação de fármacos e pode conter diferentes agentes terapêuticos que favorecem o tratamento de feridas e aceleram a regeneração tecidual $(3,5)$. Coberturas bioativas são, em geral, biocompatíveis, biodegradáveis e não tóxicas (3). As coberturas bioativas utilizadas na forma de filme apresentam inúmeras vantagens quando comparadas à outros tipos de wound dressings e formas farmacêuticas convencionais. As coberturas bioativas protegem as lesões contra a entrada de microrganismos que podem desencadear infecções oportunistas; permitem trocas gasosas entre o tecido lesionado e o meio ambiente, proporcionando a manutenção de umidade adequada para a regeneração do tecido; liberam o agente terapêutico no local, sem a necessidade de aplicar mais de um tipo de produto; facilitam o manejo das lesões; contribuem para o conforto do paciente; e, reduzem o tempo e, consequentemente, os custos do tratamento (5-7). 
Electrospinning is a promising technique for preparing films for use as a wound dressing. The technique involves the application of a high-voltage positive charge over droplets of a polymeric solution extruded from the tip of a metallic needle onto a collector, leading to the formation of microfibrous and nanofibrous matrices. This versatile method has gained considerable attention because it is simple, robust, inexpensive, can be used on a large scale, and produces matrices that have numerous advantages for use as a dressing such as a higher surface area and greater porosity than conventional matrices. The matrices produced by electrospinning have a structure similar to that of the extracellular matrix (ECM), favoring attachment, migration, and proliferation of fibroblasts, and the regeneration of tissue in the wound area (8-11).

Another focus of current research is to find compounds to replace synthetic drugs in pharmacotherapy, including in the treatment of wounds. Several medicinal plants with compounds that exhibit antimicrobial and healing activities have been studied (12-15). As the bioactive compounds in medicinal plants come from renewable sources, in general, they present less toxicity when compared to synthetic drugs (15). Essential oils and extracts from papaya, Avena (oatmeal), green tea, Centella asiatica, Rosmarinus, Chinese cinnamon, St. John's wort, safflower, copaiba, henna, mangosteen, taro, marigold, aloe, Hamamelis, myrrh, red rose, tea tree, chamomile, and pomegranate have been recognized for their usefulness in the treatment of wounds (16-19).

Plants rich in secondary metabolites having antioxidant, anti-inflammatory, antimicrobial, hemostatic, and debriding activity are the most relevant for use in wound healing (20). Among these, the use of pomegranate (Punica granatum L.) is widely reported (21-23). Solvent extracts of the leaf, seeds, pericarp, and fruit peels of pomegranate have been reported to be rich in phenolic compounds and are an important source of hydrolysable tannins, ellagitannins, and ellagic acid in addition to anthocyanins and flavonoids (24-26). The antioxidant and antimicrobial activities of pomegranate have been attributed to its secondary metabolites $(27,28)$.

Silva et al. using the disc diffusion method, evaluated the antimicrobial activity of the hydroalcoholic extract of fresh pomegranate pericarp on 38 strains of Staphylococcus aureus isolated from the milk of bovine females with mastitis. The extract showed antimicrobial action on all analyzed strains, with zones of inhibition ranging from 10 to $36 \mathrm{~mm}$ in diameter; 22 of the 38 strains were found to be resistant to
Uma técnica promissora para o preparo de filmes para uso como wound dressing é a eletrofiação. A técnica consiste na aplicação de uma carga positiva de alta tensão sobre uma gota de solução polimérica que é extrusada a partir da ponta de uma agulha metálica até um coletor, levando à formação de matrizes formadas por micro e nanofibras. Este método versátil tem ganhado considerável atenção por ser simples, robusto, barato, que pode ser usado em larga escala e produz matrizes que agregam inúmeras vantagens para o uso como wound dressing, tais como, maior área superficial e maior porosidade, quando comparados aos filmes convencionais. As matrizes preparadas por eletrofiação são semelhantes à estrutura nativa da matriz extracelular (MEC) e, por isso, favorecem a fixação, a migração e a proliferação celular e, a regeneração do tecido na área da ferida (8-11).

Outro atual foco de pesquisas é a busca por compostos bioativos para a substituição do uso de fármacos sintéticos na farmacoterapia, inclusive para o tratamento de feridas. Inúmeras plantas medicinais que possuem componentes que exibem atividades antimicrobiana e cicatrizante tem sido estudadas (12-15). Como os compostos bioativos das plantas medicinais são provenientes de fontes renováveis, em geral, apresentam menor toxicidade quando comparados aos fármacos sintéticos (15). Óleos essenciais e extratos de mamão, aveia, chá verde, centella, alecrim, canela chinesa, erva de São João, açafrão, copaíba, hena, mangostim, taro, babosa, calêndula, aloe, hamamelis, mirra, rosa-rubra, melaleuca, camomila e romã são reconhecidos pelo uso no tratamento de feridas (16-19).

Plantas ricas em metabólitos secundários com ação antioxidante, anti-inflamatória, antimicrobiana, hemostática e debridante, principalmente, são as mais interessantes para uso em processos de cicatrização (20). Entre estas, o uso de romã (Punica granatum L.) é amplamente relatado (21-23). Tem sido reportado que extratos das folhas, das sementes, do pericarpo e das cascas de frutos da romãzeira, obtidos em diferentes solventes, são ricos em compostos fenólicos, sendo uma importante fonte de taninos hidrolisáveis, elagitaninos e ácido elágico, além de antocianinas e flavonóides (24-26). As atividades antioxidante e antimicrobiana do romã são atribuídas aos seus metabólitos secundáricos $(27,28)$.

Silva et al. utilizando o método de disco-difusão avaliaram a atividade antimicrobiana de um extrato hidroalcoólico de pericarpo de romã fresco sobre 38 linhagens de Staphylococcus aureus isoladas do leite de fêmeas bovinas com mastite. O extrato estudado 
penicillin. The authors suggested that the extract was a promising alternative therapy to treat bovine mastitis (27). Lukiswanto et al. investigated the healing action of a polyethylene glycol ointment containing different concentrations of standardized pomegranate extract $(2.5,5$, and $10 \% \mathrm{w} / \mathrm{w})$ on burns induced in rats and observed that the ointment containing $10 \% \mathrm{w} / \mathrm{w}$ of the extract accelerated the healing process (28).

Several materials have been examined as possible bioactive agents for wound dressings $(2,5,7,11,29)$. Chemically, alginates are polysaccharides that are characterized as hydrophilic, anionic macromolecules with excellent biocompatibility and biodegradability. They are capable of forming hydrogen bonds and undergoing hydration, swelling, and adherance to the mucous layers of organisms. For these reasons, sodium alginate has stimulated great interest in the medical, pharmaceutical, dental, and engineering fields (4, 6-8). Similar to other natural polymers, however, disadvantages of sodium alginate include its low filmforming capacity, poor mechanical properties of the formed films, and a high rate of dissolution. For these reasons, blends of natural and synthetic polymers are usually needed (5). Poly(vinyl alcohol) (PVA) is a versatile synthetic polymer that is chemically inert with adequate mechanical resistance, excellent film-forming capacity, and good biological compatibility. PVA is mainly used in blends to stabilize polymeric dispersions, improve processability, increase the mechanical and thermal resistance, change the permeability of the formed films to gases, and promote controlled swelling and solubility $(5,29)$.

The present study aimed to evaluate the antimicrobial activity and in vitro biocompatibility of an electrospun matrix containing the extract of pomegranate peel at $1.25 \% \mathrm{w} / \mathrm{w}$ in a polymer blend of PVA and sodium alginate as a bioactive dressing. We first examined the cytotoxicity of the extract. Films were electrospun and fiber formation was confirmed using scanning electron microscopy. The hemolytic and antimicrobial activities of the matrix against bacterial and fungal strains were investigated to determine the preliminary biocompatibility and feasibility of using the film as a pomegranate-peel extract delivery system. apresentou ação antimicrobiana sobre todas as cepas analisadas, com zonas de inibição de 10 a $36 \mathrm{~mm}$ de diâmetro. Vinte e duas das 38 cepas provaram ser resistentes à penicilina. Os autores sugerem que o extrato é uma alternativa promissora para tratar a mastite bovina (27). Lukiswanto et al. investigaram a ação de uma pomada de polietilenoglicol contendo diferentes concentrações de extrato padronizado de romã $(2,5,5$ e $10 \% \mathrm{p} / \mathrm{p}$ ) no tratamento de queimaduras induzidas em ratos e, observaram que a pomada contendo $10 \% \mathrm{p} / \mathrm{p}$ do extrato acelerou o processo de cicatrização (28).

Vários materiais têm sido pesquisados para possíveis usos em wound dressings $(2,5,7,11,29)$. Quimicamente, os alginatos são polissacarídeos caracterizados como macromoléculas aniônicas hidrofílicas com excelente biocompatibilidade e biodegradabilidade. Eles são capazes de formar ligações de hidrogênio e sofrer hidratação, intumescimento e adesão às camadas mucosas dos organismos. Por estas razões, alginato de sódio tem despertado grande interesse nas áreas médica, farmacêutica, odontológica e de engenharia (4, 6-8). Por outro lado, uma desvantagem do uso do alginato de sódio sozinho, bem como de outros polímeros naturais, são a baixa capacidade filmogênica, as propriedades mecânicas pobres dos filmes formados e a alta velocidade de dissolução. Para contornar estes problemas, a formação de blendas entre polímeros naturais e sintéticos são usualmente necessárias (5). O poli(álcool vinílico) (PVA) é um polímero sintético versátil, quimicamente inerte, com resistência mecânica adequada, excelente capacidade filmogênica e boa compatibilidade biológica. O PVA é incorporado em blendas, principalmente, para promover a estabilização das dispersões poliméricas, melhorar sua processabilidade, aumentar a resistência mecânica e térmica, alterar a permeabilidade dos filmes formados aos gases e promover intumescimento e solubilidade controlados $(5,29)$.

O presente estudo teve como objetivo avaliar a atividade antimicrobiana e a biocompatibilidade in vitro de uma matriz eletrofiada contendo extrato de cascas de romã a $1,25 \% \mathrm{p} / \mathrm{p}$, em uma mistura dos polímeros PVA e alginato de sódio, para uso como cobertura bioativa. Inicialmente, a citotoxicidade do extrato foi examinada. Os filmes foram obtidos por eletrofiação e a confirmação da formação das fibras foi feita por microscopia eletrônica de varredura. A atividade hemolítica e a atividade antimicrobiana dos filmes sobre cepas de bactérias e um fungo foram investigadas para determinar a biocompatibilidade preliminar e a viabilidade do uso dos filmes como sistema de liberação do extrato das cascas dos frutos da romã. 


\section{Materials and Methods}

\section{Plant material and extract preparation}

Pomegranates (Punica granatum L.) were collected in the city of Alegre, Espírito Santo State, and processed at the Laboratory of Pharmaceutical Production of the Federal University of Espírito Santo (UFES) (Brazil). A plant-sample voucher (VIES34873) was deposited at the Herbarium of UFES located in Jerônimo Monteiro (Espírito Santo, Brazil). The fruits were washed in running water and dried with paper towels. The peels were removed with a sharp knife and left to dry at 45 ${ }^{\circ} \mathrm{C}$ for 7 days (Biopar oven, S 480 AD, Porto Alegre, Brazil). The dried material was ground in a Willey knife mill, 0.5-1.0 mesh (Marconi, MA340, Campinas, Brazil). The extract was prepared by macerating and percolating the vegetable material (coarse powder) in hydrated ethylic alcohol (92.8 INPM). About $225 \mathrm{~g}$ of powder was placed in $1.2 \mathrm{~L}$ of the solvent. The mixture was kept in a closed container until the powder swelled. The extract was filtered, the liquid was collected, and a fresh volume of the extraction solvent was added to the remaining solid. The process was repeated three times. The organic solvent was removed using a rotary evaporator (Heidolph, Laborota 4000, Schwabach, Germany). The concentrated crude extract was frozen in liquid nitrogen and lyophilized (Liotop 101 lyophilizer, São Carlos, Brazil) to yield a dry, crude product. The non-standardized crude extract was subjected to phytochemical screening tests to confirm the presence of phenolic compounds. The total phenolic content was $56.5 \%$ EAG as determined using a spectrophotometric method with Folin-Ciocalteu reagent. The concentration of $1.25 \% \mathrm{w} / \mathrm{w}$ of the extract in the electrospun film was defined based on previous work by our group, which investigated the minimum inhibitory concentration (MIC) of the same extract on strains of $S$. aureus and E. coli (29).

\section{Evaluation of extract cytotoxicity}

The cytotoxicity of the pomegranate-peel extract to murine fibroblasts L929 cell lines (NCTC clone 929) provided by a cell bank (Rio de Janeiro, Brazil) was investigated using the cell-viability method (30). Cells were cultured in Dulbecco's modified Eagle's medium (DMEM) supplemented with 10\% fetal bovine serum (FBS) in an incubator with a $5 \% \mathrm{CO}_{2}$ atmosphere at $37{ }^{\circ} \mathrm{C}$. To verify cell viability, cells that reached $90 \%$ confluency in the culture bottles were seeded at a density of $5 \times 10^{4} /$ well in 96 -well plates. Then, the cells were incubated with DMEM plus 0.1\% DMSO

\section{Material e Métodos}

\section{Material vegetal e preparo do extrato}

Frutos frescos da romã (Punica granatum L.) foram coletados na cidade de Alegre, Espírito Santo (Brasil) e processados no Laboratório de Produção Farmacêutica da Universidade Federal do Espírito Santo (UFES), campus de Alegre (Brasil). Uma amostra da planta foi depositada no Herbário da UFES (VIES34873), localizado em Jerônimo Monteiro (Espírito Santo, Brasil). Os frutos foram lavados em água corrente e secos com papel toalha. As cascas foram removidas com faca afiada e deixadas secar a $45{ }^{\circ} \mathrm{C}$ por 7 dias (estufa Biopar, S 480 AD, Porto Alegre, Brasil). O material seco foi moído em moinho de facas tipo Willey, malha 0,51,0 (Marconi, MA340, Campinas, Brasil). O extrato foi preparado macerando e percolando o material vegetal (pó grosso) em álcool etílico hidratado (92,8 $8^{\circ}$ INPM). Cerca de $225 \mathrm{~g}$ de pó foram colocadas em recipiente ao qual foi adicionado 1,2 $\mathrm{L}$ do solvente. A mistura foi mantida em recipiente fechado até o intumescimento do pó. Em seguida, o extrato foi filtrado, o líquido foi recolhido e foi adicionada nova porção do líquido extrator. O processo foi repetido 3 vezes. O solvente orgânico foi extraído por rotaevaporação (rotaevaporador Heidolph, Laborota 4000, Schwabach, Alemanha). O extrato bruto concentrado foi congelado em nitrogênio líquido e foi liofilizado (liofilizador Liotop, 101, São Carlos, Brasil), sendo obtido o extrato bruto seco. Neste extrato não padronizado, foram realizados testes de triagem fitoquímica que confirmaram a presença de compostos fenólicos. O teor de fenóis totais encontrado, após determinação por método espectrofotométrico empregando reagente de Folin-Ciocalteau, foi de $56,5 \%$ EAG. A concentração de $1,25 \%$ p/p do extrato no filme eletrofiado foi definida com base em trabalho anterior de nosso grupo, que investigou a concentração inibitória mínima (CIM) do mesmo extrato em cepas de S. aureus e E. coli (29).

\section{Avaliação da citotoxicidade do extrato}

A citotoxicidade do extrato das cascas de romã sobre fibroblastos murinos empregando linhagem L929 (NCTC clone 929), provenientes de um banco de células (Rio de Janeiro, Brasil), foi pesquisada pelo método de viabilidade celular (30). As células foram cultivadas em meio Eagle Dubelco Modificado (DMEM) suplementado com soro bovino fetal a $10 \%$ (FBS) em uma incubadora com $5 \%$ de saturação de $\mathrm{CO}_{2}$, a $37^{\circ} \mathrm{C}$. Para verificar a viabilidade celular, as células que atingiram $90 \%$ de confluência nos frascos 
(basal group), 10\% DMSO or pomegranate-peel extract (1 to $\left.100 \mu \mathrm{g} \cdot \mathrm{mL}^{-1}\right)$. In addition, $10 \mu \mathrm{L}$ of 3-(4,5dimethylthiazol-2-yl)-2,5-diphenyltetrazolium bromide (MTT, $5 \mathrm{mg} \cdot \mathrm{mL}^{-1}$ ) was added after $21 \mathrm{~h}$ to each well, and $3 \mathrm{~h}$ later, $250 \mu \mathrm{L}$ of each supernatant was removed and replaced with $100 \mu \mathrm{L}$ of DMSO. The absorbance of the samples was measured at $570 \mathrm{~nm}$. Cell viability was determined relative to the basal group that was considered to have $100 \%$ viability. The variation in viability between the control and the extract group was statistically compared using a one-way analysis of variance (ANOVA) followed by Dunnett's test.

\section{Preparation of films using electrospinning technique}

Polymeric solutions were prepared individually as follows: PVA [an average molar mass of 85,000 to $125,000 \mathrm{~g} \cdot \mathrm{mol}^{-1}$ (Sigma-Aldrich, USA)] was dissolved in purified water $(12 \% \mathrm{w} / \mathrm{v})$ using a mechanical stirrer (Fisatom, 713D, São Paulo, Brazil) at $90-100{ }^{\circ} \mathrm{C}$ until the polymer was completely solubilized. Sodium alginate $(\mathrm{NaAlg}$, brown algae; viscosity from 5-40 cP; Sigma-Aldrich, USA) was dispersed in purified water $(4 \% \mathrm{w} / \mathrm{v})$ at $60{ }^{\circ} \mathrm{C}$ using the mechanical stirrer. After preparation, polymer solutions were combined at a 9:1 ratio of PVA:NaAlg and mixed for $45 \mathrm{~min}$ using magnetic stirrer (Fisatom 753A, São Paulo, Brazil). Pomegranate-peel extract was added at $1.25 \% \mathrm{w} / \mathrm{v}$ and the mixture was stirred for another $45 \mathrm{~min}$.

Electrospinning was performed (Instor equipment, São José dos Campos, Brazil) and processed according to the scheme shown in Figure 1. The process parameters were as follows: glass syringe (Arti Glass, Due Carrare, Italy) with an orthogonal 0.7 gauge cutting metal needle, filled with $10 \mathrm{~mL}$ of the working solution; ejection rate, $1.7 \mathrm{~mL} \cdot \mathrm{h}^{-1}$; applied voltage, $25 / 0 \mathrm{kV}$; distance between the needle and collector, $15.5 \mathrm{~cm}$; room temperature $\left(25-28{ }^{\circ} \mathrm{C}\right)$; relative humidity inside the chamber $55 \%$. The films were collected on a flat rotating collector disc covered with aluminum foil at $90 \mathrm{rpm}$. The apparatus remained powered on and ejected the nanofibers when the entire syringe content was used. de cultura foram semeadas a uma densidade de $5 \times 10^{4} /$ poço em placas de 96 poços. Em seguida, as células foram incubadas com DMEM acrescido de $0,1 \%$ de DMSO (grupo basal), 10\% de DMSO ou extrato de casca de romã (1 a $\left.100 \mu \mathrm{g} \cdot \mathrm{mL}^{-1}\right)$. Além disso, 10 $\mu \mathrm{L}$ de brometo de 3-(4,5-dimetiltiazol-2-il)-2,5difeniltetrazólio (MTT, $5 \mathrm{mg} \cdot \mathrm{mL}^{-1}$ ) foram adicionados após $21 \mathrm{~h}$ a cada poço e, $3 \mathrm{~h}$ depois, $250 \mu \mathrm{L}$ de cada sobrenadante foram removidos e substituídos por 100 $\mu \mathrm{L}$ de DMSO. A absorbância das amostras foi medida a $570 \mathrm{~nm}$. A viabilidade celular foi determinada em relação ao grupo basal cuja viabilidade foi considerada de $100 \%$. A variação na viabilidade entre o controle e o grupo de extrato foi comparada estatisticamente usando análise de variância unilateral (ANOVA), seguida pelo teste de Dunnett.

\section{Preparo dos filmes pela técnica de eletrofiação}

As soluções poliméricas foram preparadas individualmente, da seguinte maneira: poli(álcool vinílico) (PVA) [massa molar média de 85.000 a 125.000 g. $\mathrm{mol}^{-1}$ (Sigma-Aldrich, USA)] foi dissolvido em água purificada $(12 \% \mathrm{p} / \mathrm{v})$ empregando agitador mecânico (Fisatom 713D, São Paulo, Brasil), à $90-100{ }^{\circ} \mathrm{C}$, até completa solubilização do polímero. Alginato de sódio (NaAlg de algas marrons; viscosidade de 5 a $40 \mathrm{cP}$; Sigma-Aldrich, USA) foi disperso em água purificada $\left(4 \%\right.$ p/v) a $60{ }^{\circ} \mathrm{C}$, no agitador mecânico. Após preparo, as soluções poliméricas foram misturadas na proporção 9:1 (PVA:NaAlg) por $45 \mathrm{~min}$ em agitador magnético (Fisatom 753A, São Paulo, Brasil). O extrato de casca de romã foi incorporado diretamente na mistura a $1,25 \% \mathrm{p} / \mathrm{V}$, sob agitação magnética por mais $45 \mathrm{~min}$.

A eletrofiação foi realizada em equipamento Instor (São José dos Campos, Brasil) e processado conforme o esquema apresentado na Figura 1. Os parâmetros do processo foram os seguintes: seringa de vidro (Arti Glass, Due Carrare, Italy) com agulha metálica de corte ortogonal de calibre 0,7 , preenchida com $10 \mathrm{~mL}$ da solução de trabalho; taxa de ejeção igual a 1,7 m. $\mathrm{h}^{-1}$; voltagem aplicada de $25 / 0 \mathrm{kV}$; distância entre a agulha e o coletor de $15,5 \mathrm{~cm}$; temperatura ambiente $\left(25-28{ }^{\circ} \mathrm{C}\right)$; e, umidade relativa dentro da câmara de $55 \%$. Os filmes foram coletados em um disco coletor rotativo plano coberto com folha de alumínio a $90 \mathrm{rpm}$. $\mathrm{O}$ aparelho permaneceu ligado e ejetou as nanofibras até que todo o conteúdo da seringa fosse esgotado. 


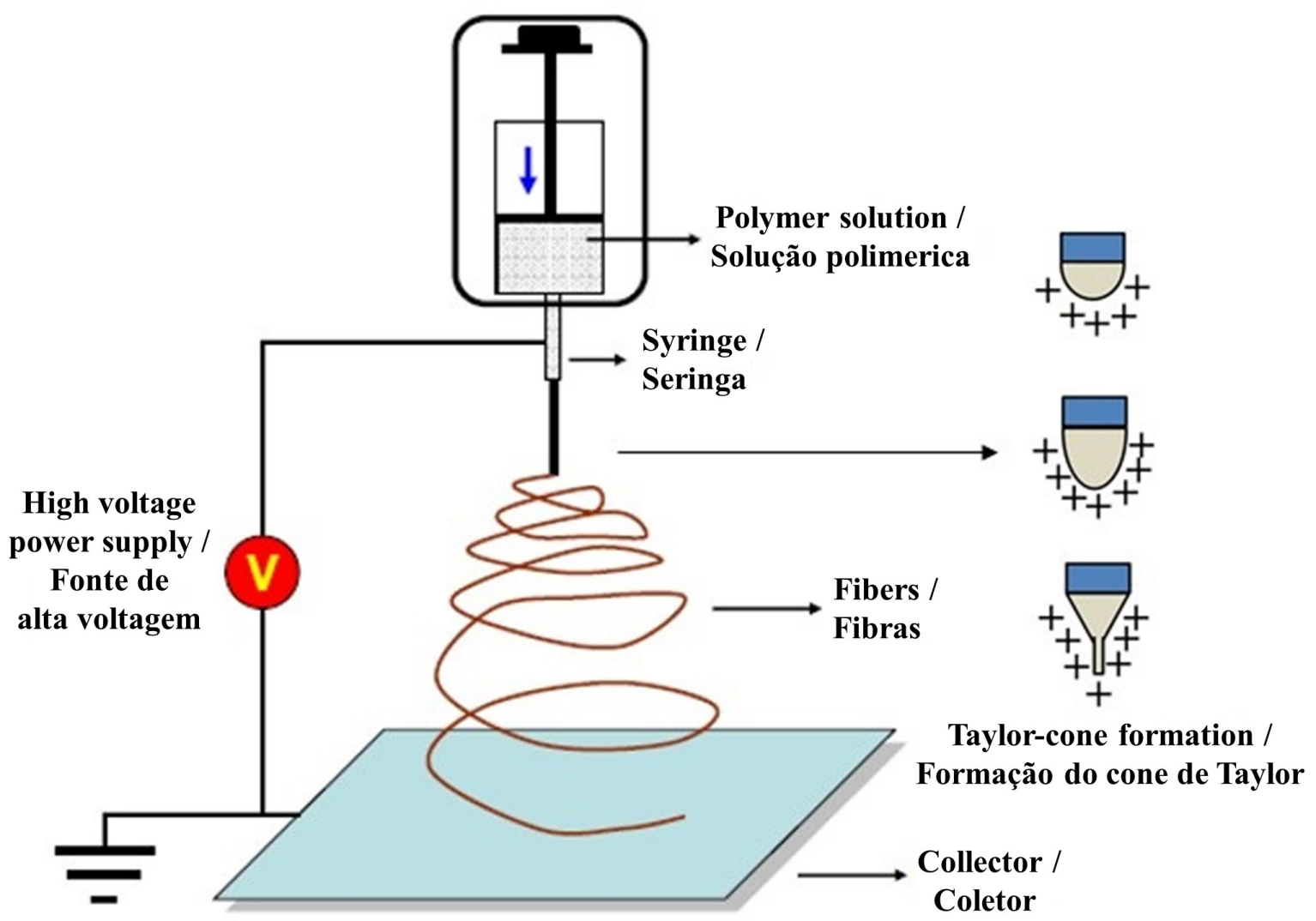

Figure 1 - Representation of an electrospinning process. Adapted from: Vass et al., 2019 (31).

Figura 1 - Representação do processo de eletrofiação. Adaptado de: Vass et al., 2019 (31).

\section{Scanning electron microscopy (SEM)}

Film morphology was studied using scanning electron microscopy (SEM) (Hitachi TM4000, Tokyo, Japan). Samples for SEM were coated with a thin layer of gold $(10 \mathrm{~nm})$ using a sputter coater (Desk V, Denton Vacuum). After being attached to the holder with double-sided carbon tape, photomicrographs were obtained at an accelerating voltage of $15 \mathrm{kV}$ and $1000 \mathrm{X}$ and 5000X magnifications. The average fiber diameters were determined from the photomicrographs obtained from at least 100 randomly chosen measurements using image analysis software (ImageJ, US NIH, Bethesda, MD, USA).

\section{Hemolytic index}

Preliminary biocompatibility was assessed by determining the hemolytic index as follows. Samples of the films $(1 \times 1 \mathrm{~cm})$ were inserted in Eppendorf microtubes containing $0.9 \mathrm{~mL}$ of blood and $0.1 \mathrm{~mL}$ of acid citrate dextrose (ACD). The microtubes were incubated in a water bath (Fanem 1100, São Paulo, Brazil) at $37{ }^{\circ} \mathrm{C}$ for $3 \mathrm{~h}$. The tubes were gently inverted
Microscopia eletrônica de varredura (MEV)

A morfologia dos filmes foi analisada por microscopia eletrônica de varredura (MEV) (Hitachi, modelo TM4000, Tóquio, Japão). Amostras para o MEV foram recobertas com uma fina camada de ouro $(10 \mathrm{~nm})$, em metalizador à vácuo (Desk V, Denton Vacuum). Depois de afixados no suporte com fita de carbono dupla face, fotomicrografias foram obtidas com aceleração de 15 $\mathrm{kV}$ e aumentos de 1000 e 5000 vezes. Os diâmetros médios das fibras foram determinados a partir das fotomicrografias obtidas e foram realizadas pelo menos 100 medições aleatoriamente, utilizando o software de análise de imagem ImageJ (US NIH, Bethesda, MD, USA).

\section{Índice hemolítico}

Biocompatibilidade preliminar foi pesquisada mediante determinação do índice de hemólise, como a seguir. Amostras dos filmes $(1 \times 1 \mathrm{~cm})$ foram picotadas e inseridas em microtubos Eppendorf contendo 0,9 mL de sangue, aos quais foram adicionados $0,1 \mathrm{~mL}$ de solução citrato ácido dextrose (ACD). Os microtubos 
twice every $30 \mathrm{~min}$ to ensure contact between the films and blood. After the incubation time the microtubes were centrifuged at $3000 \mathrm{rpm}$ for $20 \mathrm{~min}$ using a centrifuge (Hettich Mikro 200, Tuttlingen, Germany). The supernatants were transferred to a 96-well plate and the absorbance was read using an ultraviolet-visible (UV-VIS) spectrometer (Thermo Fisher, Multiskan GO, Vantaa, Finlandia) at $540 \mathrm{~nm}$. Purified water and phosphate-buffered saline (PBS) were used as the positive and negative controls, respectively. Tests were performed in triplicate. The hemolysis percentage was calculated using Equation 1 where, $\mathrm{A}_{\text {sample }}, \mathrm{A}_{\text {negative Control' }}$, and $\mathrm{A}_{\text {positive Control }}$ are the absorbance values of the film, negative control, and positive control, respectively. The results are expressed as the means \pm standard deviation (SD).

$$
\text { Hemolysis }(\%)=\frac{\left(\mathrm{A}_{\text {sample }}-\mathrm{A}_{\text {negative nontror }}\right) \times 100}{\left(\mathrm{~A}_{\text {positive control }}-\mathrm{A}_{\text {negative control }}\right)}
$$

\section{Antimicrobial activity}

The in vitro antimicrobial activity was evaluated using the disc diffusion method according to the CLSI protocols. Tests were carried out in triplicate using E. coli (ATCC 25922), S. aureus (ATCC 25923), $S$. epidermidis (ATCC 12228), and Candida albicans (ATCC 24433). The microorganisms were cultured in Brain-Heart Infusion (BHI) broth at $35.5^{\circ} \mathrm{C}$ for 24 $\mathrm{h}$ and the concentrations of the bacterial suspensions were adjusted according to 0.5 on the McFarland scale using sterile saline $(0.85 \%$ sodium chloride).

Film discs were cut into circular pieces with a 6-mm diameter and placed on the surfaces of inoculated Mueller-Hinton Agar (MHA) plates. Chloramphenicol $\left(30 \mu \mathrm{g} \cdot \mathrm{disc}^{-1}\right)$ and amphotericin B $\left(20 \mu \mathrm{g} \cdot \mathrm{disc}^{-1}\right)$ were used as standards (positive controls) to determine antimicrobial susceptibility. The culture plates were incubated during $24 \mathrm{~h}$ in an incubator at $37{ }^{\circ} \mathrm{C}$. The diameters of the inhibition zones were measured in $\mathrm{mm}$. The results are expressed as means $\pm \mathrm{SD}$. foram incubadas em banho-maria (Fanem, modelo 1100, São Paulo, Brasil) a $37^{\circ} \mathrm{C}$ por 3 h. Os tubos foram suavemente invertidos duas vezes a cada 30 min para garantir o contato íntimo entre os filmes e o sangue. Decorrido o tempo de incubação, os tubos foram centrifugados a $3000 \mathrm{rpm}$ por $20 \mathrm{~min}$ (centrífuga Hettich, Mikro 200, Tuttlingen, Alemanha). O sobrenadante dos microtubos foi transferido para uma placa de 96 poços e foi realizada a leitura da absorbância em espectrofotômetro (Thermo Fisher, Multiskan GO, Vantaa, Finlândia) a $540 \mathrm{~nm}$. Água purificada e tampão PBS foram utilizadas como controle positivo e negativo, respectivamente. $\mathrm{O}$ teste foi realizado em triplicata. A porcentagem de hemólise foi calculada a partir da Equação 1, onde $\mathrm{A}_{\text {amostra, }}, \mathrm{A}_{\text {controle negativo, }}, \mathrm{A}_{\text {controle positivo }}$ são os valores de absorvância do filme, controle negativo e controle positivo, respectivamente. Os resultados são expressos como a média \pm desvio padrão (SD).

$$
\text { Hemólise }(\%)=\frac{\left(\mathrm{A}_{\text {sample }}-\mathrm{A}_{\text {controlo negativo }}\right) \times 100}{\left(\mathrm{~A}_{\text {controlo positivo }}-\mathrm{A}_{\text {controlo negativo }}\right)} \quad \text { Eq. } 1
$$

\section{Atividade antimicrobiana}

A atividade antimicrobiana in vitro foi avaliada empregando o método de disco-difusão, de acordo com protocolos CLSI. Os testes foram realizados em triplicata empregando cepas de E. coli (ATCC 25922), $S$. aureus (ATCC 25923), S. epidermidis (ATCC 12228) e Candida albicans (ATCC 24433). Para este experimento, os microrganismos foram previamente cultivados em meio ágar Brain Heart Infusion (BHI) à $35,5^{\circ} \mathrm{C}$, por $24 \mathrm{~h}$ e a concentração da suspensão dos microrganismos foi ajustada pela escala McFarland para 0,5 , utilizando solução salina estéril $(0,85 \%)$.

Discos dos filmes eletrofiados foram cortados em pedaços circulares com $6 \mathrm{~mm}$ de diâmetro e colocados nas superfícies de placas contendo meio Mueller-Hinton Agar (MHA) previamente inoculadas. Cloranfenicol (30 $\mu \mathrm{g} \cdot$ disco $\left.^{-1}\right)$ e anfotericina B (20 $\mu \mathrm{g} \cdot$ disco $\left.^{-1}\right)$ foram usados como padrão (controles positivos) para determinar a suscetibilidade aos antimicrobianos. As placas de cultura foram incubadas durante $24 \mathrm{~h}$ em incubadora a $37^{\circ} \mathrm{C}$. Os diâmetros das zonas de inibição foram medidos em $\mathrm{mm}$. Os resultados foram expressos como médias \pm DP. 


\section{Results}

The cytotoxicity of the pomegranate-peel extract was investigated using the cell viability test $(30,32)$. For all tested concentrations of the extract, the cell viability was $>90 \%$, suggesting that the extract was nontoxic. At concentrations $>30 \mu \mathrm{g} \cdot \mathrm{mL}^{-1}$, cell proliferation was stimulated. In contrast, DMSO reduced cell viability to $36.5 \%$, whereas in the presence of the medium containing enriched DMEM, it was nearly $100 \%$ (Figure 2).

The beneficial effect of pomegranate-peel extract on the viability of the cells suggests that it contains bioactive components capable of stimulating cell proliferation; this effect may be associated with the presence of polyphenols. Baldovskà et al. observed that dried pomegranate extracts, rich in punicalagin, dissolved in culture medium positively modulated the viability of human ovarian granulosa cell line in vitro (33). The beneficial properties of punicalagin, as a major phytochemical of pomegranate, on cell lineages were described previously by Packovà et al. (34).

\section{Resultados}

A citotoxicidade do extrato de casca de romã foi investigada por meio do teste de viabilidade celular $(30,32)$. Para todas as concentrações testadas do extrato, a viabilidade celular foi superior a $90 \%$, sugerindo que o extrato foi não tóxico. Em concentração acima de $30 \mu \mathrm{g} . \mathrm{mL}^{-1}$ a proliferação celular foi estimuladas. Em contraste, o DMSO reduziu a viabilidade celular para cerca de $36,5 \%$ enquanto a viabilidade na presença do meio contendo DMEM enriquecido foi próxima de 100\% (Figura 2).

O efeito benéfico do extrato de romã sobre viabilidade das células estudadas sugere que ele apresenta, entre seus metabólitos secundários, componentes bioativos capazes de estimular a proliferação celular, o que pode estar associados à presença de polifenóis. Baldovskà et al. observaram que extratos secos de romã ricos em punicalagina, previamente dissolvidos em meio de cultura, modularam positivamente a viabilidade de linhagens celulares de células granulosas ovarianas humanas em experimentos in vitro (33). Propriedades benéficas da punicalagina como fitocomposto majoritário do romã sobre linhagens celulares foram descritas anteriormente por Packovà et al. (34).

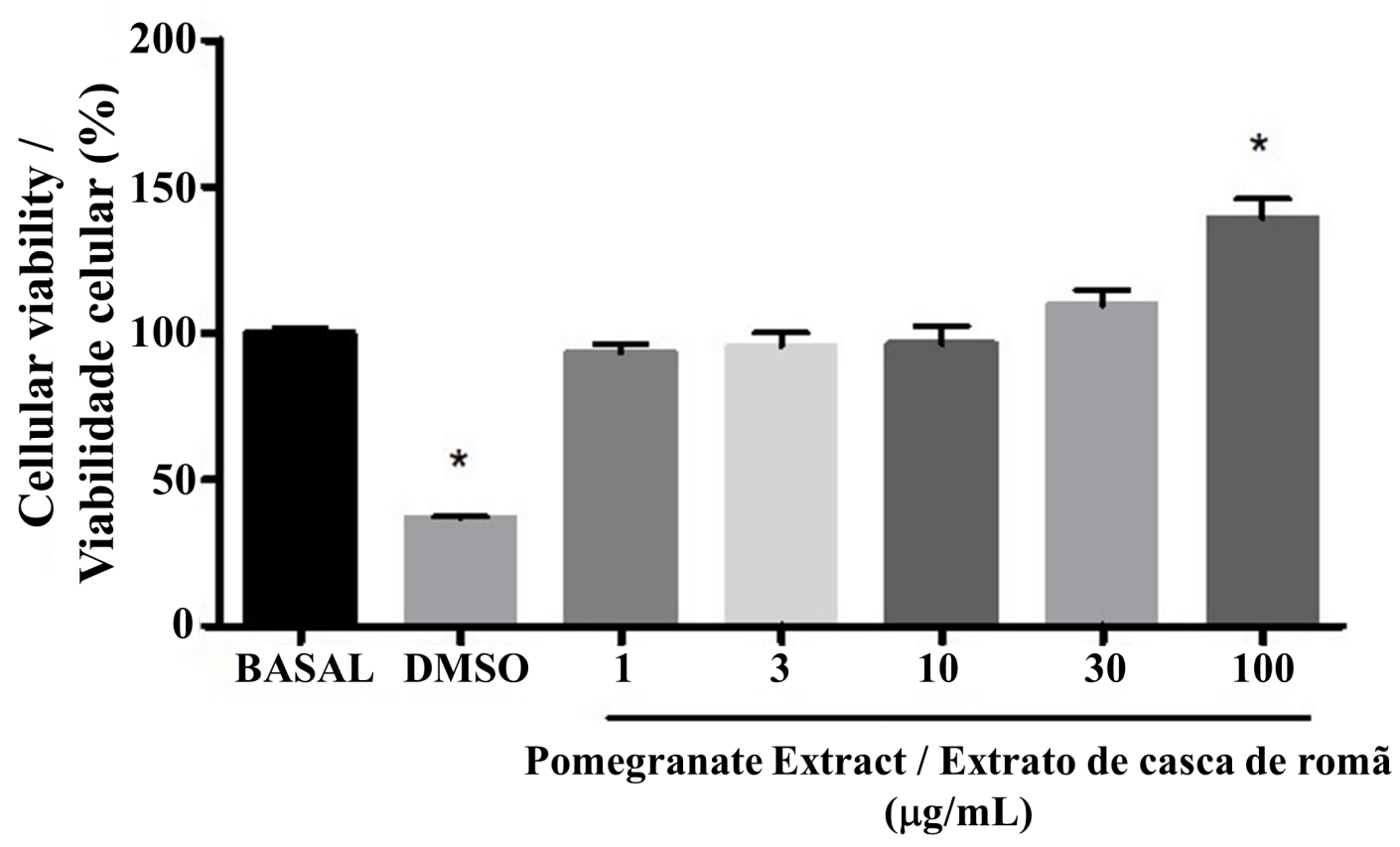

Figure 2 - Effect of different concentrations of hydroethanolic pomegranate peel extract on the viability of L929 cells. $* \mathrm{p}<0.05$, compared to baseline group.

Figura 2 - Efeito das diferentes concentrações de extrato hidroetanólico das cascas de romã sobre a viabilidade de células L929. *p $<0.05$, comparado com o grupo basal. 
After extract was confirmed to be non-toxic, films were electrospun using the characterized extract at the selected concentration as described above. The matrices formed appeared intact, opaque, and white (without the extract) or slightly yellow (with the extract) (Figure 3).

SEM images confirmed the formation of fibers and determination of their morphology (Figure 4). Photomicrographs showed the formation of fibers without beads in both samples. The fibers were oriented; they were not tangled but were interconnected. Films with the extract showed particles adsorbed on the surface. The examination of the images suggested that the addition of the extract did not negatively affect fiber formation. The average diameter of the nanofibers in the films with the extract was $393.91 \mathrm{~nm}( \pm 122.59 \mathrm{~nm}$; $\mathrm{n}=100)$ and $322.85 \mathrm{~nm}( \pm 188.52 \mathrm{~nm} ; \mathrm{n}=100)$ without extract, indicating high heterogeneity.

Electrospinning allows the preparation of different matrices for drug delivery systems based on natural and synthetic polymers that are of great interest in the pharmaceutical field. The incorporation of bioactive compounds in these films has been investigated in numerous studies (35-37). Silva et al. prepared poly( $\varepsilon-$ caprolactone) (PCL) films containing two types of Caesalpinia spinosa extracts using electrospinning (38). Yao et al. prepared electrospun films of gelatin and PVA containing different concentrations of Centella asiatica extract and investigated the healing activity of the films in rats. The study showed that films containing 31.2 $\mathrm{mg}$ of the extract promoted tissue healing with greater collagen deposition in the lesions (39).

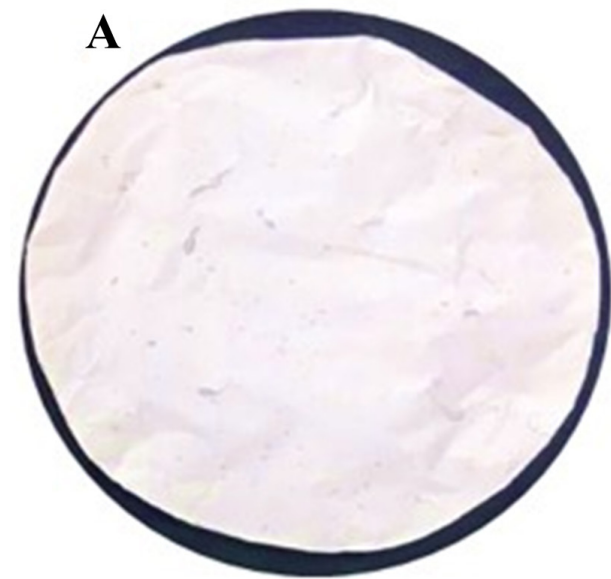

Depois de comprovada a não toxicidade do extrato e, filmes foram eletrofiados usando o extrato caracterizado e na concentração selecionada, como definido anteriormente. As matrizes formadas se mostraram íntegras, opacas, de cor branca (sem extrato) ou ligeiramente amarelados (com extrato) (Figura 3).

As fotomicrografias obtidas por MEV confirmaram a formação das fibras e permitiram a observação da morfologia das mesmas (Figura 4). Fotomicrografias mostraram a formação de fibras sem defeitos em ambas as amostras. As fibras se mostraram orientadas, não emaranhadas e interconectadas. Filmes com extrato apresentaram partículas adsorvidas na superfície das fibras. A análise das imagens sugere que a adição do extrato não afetou negativamente na formação das fibras. O diâmetro médio das nanofibras nos filmes com extrato foi de $393,91 \mathrm{~nm}( \pm 122,59 \mathrm{~nm} ; \mathrm{n}=100)$ e, no filme sem extrato, foi de $322,85 \mathrm{~nm}( \pm 188,52 \mathrm{~nm}$; $\mathrm{n}=$ $100)$, indicando grande heterogeneidade.

O processo de eletrofiação permite a preparação de diferentes matrizes para sistemas de liberação de fármacos baseadas em polímeros naturais e sintéticos, sendo de grande interesse na área farmacêutica. A incorporação de compostos bioativos nestes filmes vem sendo investigada em numerosos estudos (35-37). Silva et al. prepararam filmes de poli(E-caprolactona) (PCL) contendo dois tipos de extrato de Caesalpinia spinosa por eletrofiação (38). Yao et al. prepararam filmes eletrofiados de gelatina e PVA contendo diferentes concentrações de extrato de Centella asiatica

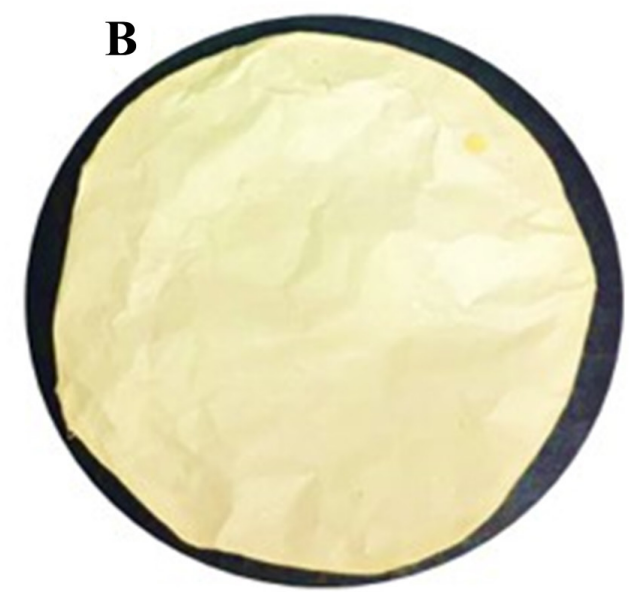

Figure 3 - Representative images of films prepared using electrospinning (A) without and (B) with $1.25 \% \mathrm{w} / \mathrm{w}$ extract.

Figura 3 - Imagens representativas dos filmes preparados por eletrofiação (A) sem e (B) com extrato a $1,25 \% \mathrm{p} / \mathrm{p}$. 


\section{In vitro biological evaluation of films}

The films described above were analyzed in vitro to assess their potential usefulness for the intended purpose. The assessment of hemolytic activity can provide information about the biocompatibility of a system or device and is evaluated by determining the capacity of the biomaterial to trigger an adequate biological response in the body without causing an inflammatory response or toxicity $(40,41)$. The percentage of hemolysis induced by the film without and with extract was $1.7 \%( \pm 0.15)$ and $3.2 \%( \pm 1.1)$, respectively.

According to Kamoun et al. materials can be classified according to their degree of induction of hemolysis as non-hemolytic $(<2 \%)$, slightly hemolytic (between $2 \%$ and 5\%), and hemolytic (>5\%) (40). Our films without the extract could be classified as non-hemolytic, whereas those incorporating the pomegranate-peel extract at $1.25 \% \mathrm{w} / \mathrm{w}$ were slightly hemolytic. Costa et al. (29) reported similar data in the study of films containing the same extract at concentrations of $1.25 \%$ and $2.5 \% \mathrm{w} / \mathrm{w}$ that were prepared from blends of PVA, starch, and poly(acid acrylic) using a casting method. However, according to Pal et al., materials with a hemolysis index $<5 \%$ can be considered highly hemocompatible, indicating good biocompatibility (41).
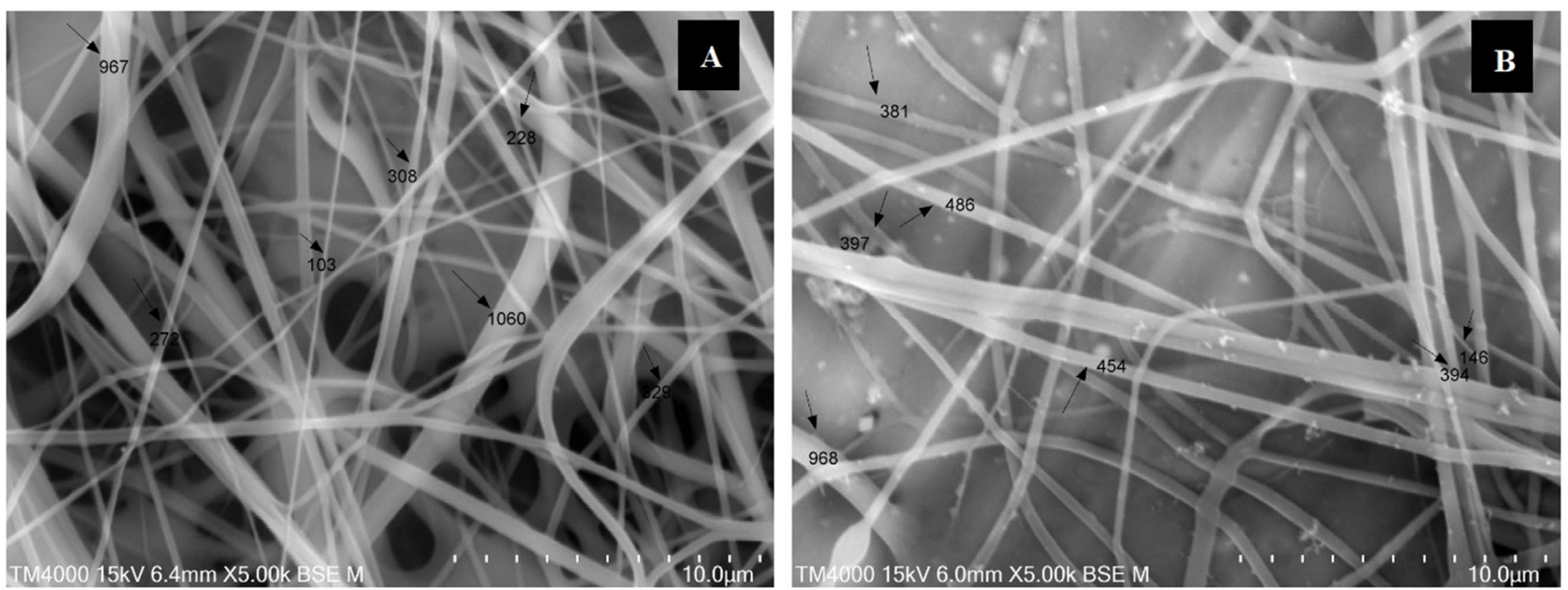

Figure 4 - Photomicrographs of films (A) without and (B) with $1.25 \% \mathrm{w} / \mathrm{w}$ extract at $5000 \times$ magnification. Dimensions are indicated in nanometers $(n=100$ nanofibers; scale bar: $10 \mu \mathrm{m})$.

Figura 4 - Fotomicrografias dos filmes (A) sem e (B) com extrato a 1,25\% p/p, com aumento de 5000× vezes (escala da barra: $10 \mu \mathrm{m})$. Dimensões indicadas em nanômetros $(\mathrm{n}=100$ nanofibras; barra de escala: $10 \mu \mathrm{m})$.

e pesquisaram a atividade cicatrizante dos filmes em ratos. O estudo demonstrou que filmes contendo 31,2 mg de extrato promoveram cicatrização tecidual com maior deposição de colágeno nas lesões (39).

\section{Avaliação biológica in vitro do filme}

Os filmes foram submetidos a análises in vitro para avaliação do potencial uso do mesmo com a finalidade pretendida. A determinação da atividade hemolítica é uma técnica preliminar para avaliação da biocompatibilidade do sistema ou dispositivo, mediante pesquisa da capacidade do biomaterial desencadear uma resposta biológica adequada no organismo, sem causar resposta inflamatória ou toxicidade $(40,41)$. A porcentagem de hemólise induzida pelo filme sem extrato e com extrato foi $1,7 \%( \pm 0,15)$ e $3,2 \%( \pm 1,1)$, respectivamente.

Segundo Kamoun et al. os materiais podem ser classificados quanto ao seu grau de hemólise como não hemolíticos $(<2 \%)$, levemente hemolíticos (entre $2 \%$ e $5 \%$ ) e, hemolíticos (>5\%) (40). Os filmes sem a incorporação do extrato podem ser classificados como não hemolíticos enquanto aqueles contendo o extrato de romã na concentração de $1,25 \% \mathrm{p} / \mathrm{v}$ foram ligeiramente hemolíticos. Costa et al. (29) reportaram resultados dados semelhantes para filmes contento o mesmo extrato nas concentrações de $1,25 \%$ e $2,5 \%$ p/p, preparados por moldagem e evaporação do solvente. Segundo Pal et al., materiais cujo índice de hemólise é $<5 \%$ podem ser considerados altamente hemocompatíveis, indicando boa biocompatibilidade (41). 
The disc diffusion test was used to investigate the sensitivity of different strains of Gram-positive and Gram-negative bacteria and a fungus to our films containing the extract at the selected concentration. Figure 5 shows images of the assay for each of the studied strains. The inhibition-zone values are listed in Table 1.

The tests showed the formation of inhibition zones with the positive controls (chloramphenicol and amphotericin B) set up according to the standards recommended for each studied strain. There was no growth inhibition when the no extract film was used.

These two results collectively indicated that the tests were conducted properly. The antimicrobial activity of the film containing the pomegranate-peel extract was confirmed by the formation of inhibition zones for $S$. aureus, $S$. epidermidis, and $C$. albicans with values of $10.0 \pm 1.0,11.0 \pm 0.0$, and $11.7 \pm 1.5 \mathrm{~mm}$, respectively, indicating that the extract incorporated in the film was released into the medium at an appropriate concentration to inhibit microbial growth.
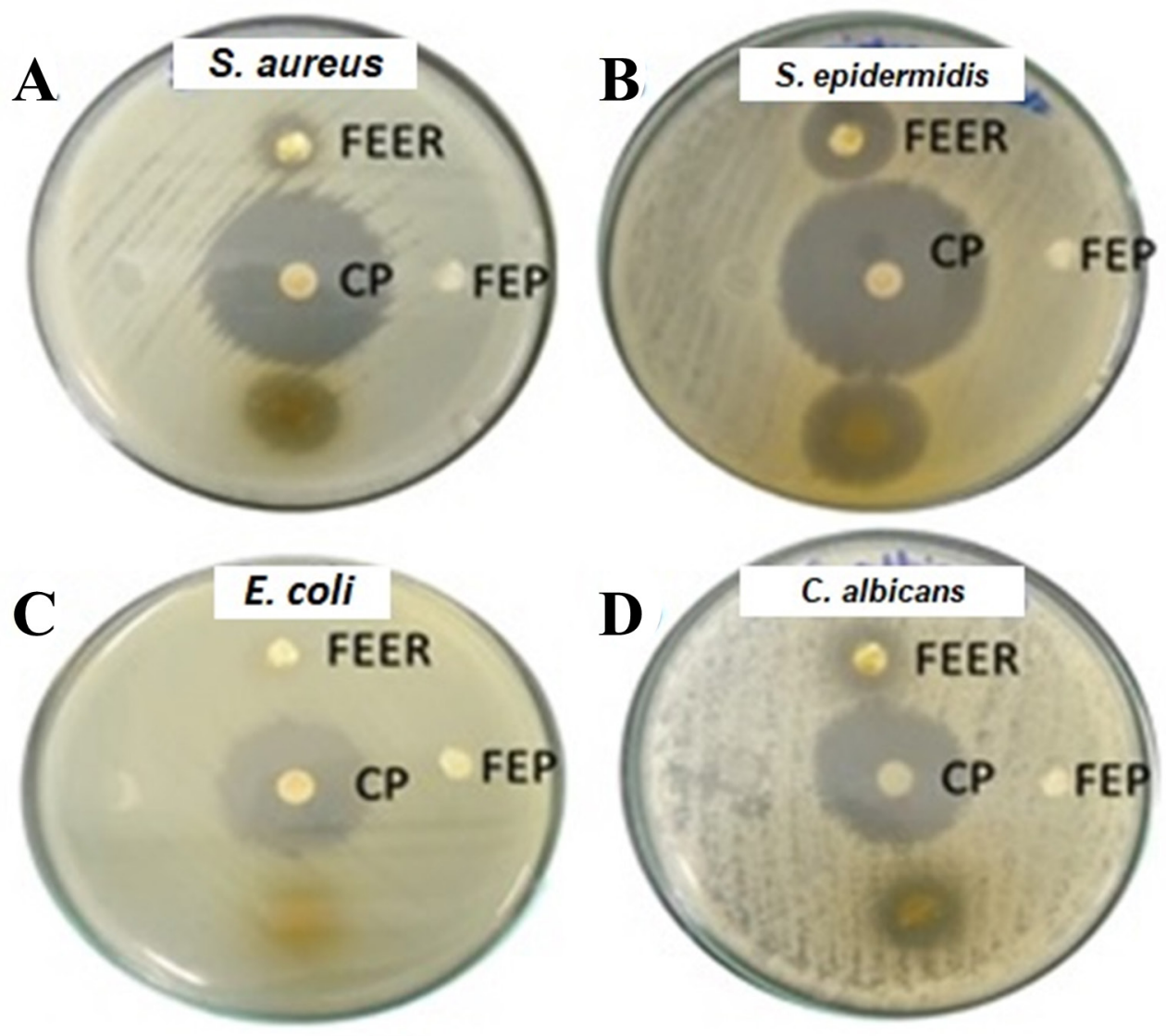

Figure 5 - Representative images of disc diffusion test: (A) S. aureus, (B) S. epidermidis, (C) E. coli, and (D) C. albicans. $\mathrm{FEP}=$ pure film, FEER $=$ film with the extract, $\mathrm{CP}=$ positive control.

Figura 5 - Imagens representativas do teste de disco-difusão: (A) S. aureus, (B) S. epidermidis, (C) E. coli, e (D) C. albicans. $\mathrm{FEP}=$ filme puro, $\mathrm{FEER}=$ filme com extrato, $\mathrm{CP}=$ controle positivo. 
Table 1 - Inhibition-zone diameters (mm, means \pm standard deviation [SD]).

Tabula 1 - Diâmetro das zonas de inibição (mm, média \pm desvio padrão [DP]).

\begin{tabular}{ccccc}
\hline Samples /Amostras & \multicolumn{4}{c}{ Inhibition zone $(\mathbf{m m})[ \pm \mathbf{S D}]$ / Zona de inibição $(\mathbf{m m})[ \pm \mathbf{D P}]$} \\
\cline { 2 - 5 } Antibiotics / Antibióticos & S. aureus & E. coli & S. epidermidis & C. albicans \\
\hline FEP & $0.0( \pm 0.0)$ & $0.0( \pm 0.0)$ & $0.0( \pm 0.0)$ & $0.0( \pm 0.0)$ \\
FEER & $10.0( \pm 1.0)$ & $0.0( \pm 0.0)$ & $11.0( \pm 0.0)$ & $11.7( \pm 1.5)$ \\
Chloramphenicol / Cloranfenicol & $20.0( \pm 0.1)$ & $23.0( \pm 0.2)$ & $22.0( \pm 0.5)$ & $\mathrm{NT}$ \\
Amphotericin B / Anfotericina B & $\mathrm{NT}$ & $\mathrm{NT}$ & $\mathrm{NT}$ & $20.0( \pm 0.5)$ \\
\hline
\end{tabular}

$\mathrm{FEP}=$ pure film, FEER $=$ film with extract, $\mathrm{NT}=$ not tested $/ \mathrm{FEP}=$ filme puro, $\mathrm{FEER}=$ filme com extrato, $\mathrm{NT}=\mathrm{Não}$ testado

The antimicrobial efficacy of our extract on the Grampositive bacteria and fungus could be associated with the presence of hydrolysable tannins, flavonoids, alkaloids, and organic acids including ellagic acid, gallic acid, quercetin, luteolin, campherol, naringenin, punicalin, and punicalagin (42-44). The extract used in the present study showed positive results for the presence of tannins and a total phenolic content $>56 \%$ EAG that strongly supports the observed antimicrobial activity. Published studies suggest that the tannins present in different types of pomegranate-peel extracts can form complexes with proteins and enzymes that mediate antimicrobial activity and render them inactive (42-46).

The data of the present study corroborate the published literature on the activity of pomegranate extracts against Gram-positive bacteria (47-52). Trindade et al. reported that a $20 \%$ tincture of pomegranate-fruit peel inhibited the growth of $S$. aureus strains even at dilutions of 1:2, 1:4, and 1:8 (48). Among the cultures tested by Daham et al., the methanolic extract of pomegranate-peel showed the highest activity against S. aureus with zones of inhibition of 10 to $25 \mathrm{~mm}$ (49). Abdollahzadeh et al. observed that the strains of $S$. epidermidis and $S$. aureus were sensitive to the methanolic extract of pomegranate at concentrations of 4,8 , and $12 \mathrm{mg} \cdot \mathrm{mL}^{-1}$ (50). Machado et al. reported that gel formulations containing $2 \% \mathrm{w} / \mathrm{w}$ of the ethanolic extract of pomegranate-peel with at least $0.49 \% \mathrm{w} / \mathrm{w}$ of total punicalagin may be useful in wound healing (51). The ethyl acetate extract of the pomegranate-peel effectively inhibited $S$. aureus at a concentration of $0.25 \% \mathrm{w} / \mathrm{w}$. Silva et al. evaluated the feasibility of using aqueous extracts of the leaves and peels of pomegranate fruits to treat bovine mastitis and found that strains of $S$. aureus isolated from the milk of bovine females with mastitis were sensitive to concentrations between 1 and $25 \% \mathrm{w} / \mathrm{w}$ (52). Results showed that the pomegranatepeel extract had greater activity than the leaf extract.
A eficácia antimicrobiana de nosso extrato sobre as bactérias Gram-positivas e fungos pode estar associada à presença de taninos hidrolisáveis, flavonóides, alcalóides e ácidos orgânicos, incluindo ácido elágico, ácido gálico, quercetina, luteolina, camferol, naringenina, punicalina e punicalagina (42-44). O extrato utilizado no presente estudo apresentou resultados positivos para a presença de fenóis totais, com conteúdo fenólico total $>56 \%$ EAG, o que corrobora fortemente a atividade antimicrobiana observada. Estudos publicados sugerem que os taninos presentes em diferentes tipos de extratos de casca de romã podem formar complexos com proteínas e enzimas mediadoras da atividade antimicrobiana, inativando os microrganismos (42-46).

Dados obtidos no presente trabalho corroboram outros disponíveis na literatura, uma vez que foi observada ação inibitória do extrato sobre cepas de bactérias Gram-positivas (47-52). Segundo Trindade et al. uma tintura feita a partir da casca dos fruots da romã a $20 \%$ foi capaz de inibir o crescimento de cepas de $S$. aureus, mesmo quando diluída nas proporções 1:2, 1:4 e 1:8 (48). Entre as culturas selecionadas por Daham et al. para estudo, a maior atividade para um extrato metanólico das cascas de romã foi observada contra S. aureus, com zonas de inibição de 10 a $25 \mathrm{~mm}$ (49). Abdollahzadeh et al. observaram que linhagens de $S$. epidermidis e $S$. aureus foram sensíveis ao extrato metanólico de romã, nas concentrações de 4,8 e 12 mg.mL $L^{-1}$ (50). Segundo Machado et al. formulações de géis contendo $2 \% \mathrm{p} / \mathrm{p}$ de extrato etanólico das cascas de romã, contendo pelo menos $0,49 \% \mathrm{p} / \mathrm{p}$ de punicalagina total, podem ser úteis na cicatrização de feridas. $\mathrm{O}$ extrato das cascas de romã preparado em acetato de etila, foi efetivo na inibição de $S$. aureus, na concentração de a $0,25 \% \mathrm{p} / \mathrm{v}(51)$. Silva et al. avaliaram a viabilidade do uso de extratos aquosos das folhas e das cascas dos frutos da romãzeira para tratamento da mastite bovina, mediante pesquisa da sensibilidade dos mesmos em concentrações entre 1 e $25 \% \mathrm{p} / \mathrm{v}$, sobre cepas de $S$. 
However, both extracts were considered suitable for the intended use. Pomegranate has been incorporated alone or with honey in starch gels at concentrations of 2.5 and $10 \% \mathrm{w} / \mathrm{w}$. The gels were impregnated into gauze for use on wounds. The susceptibility of strains of $P$. aeruginosa and $S$. aureus isolated from wounds was evaluated against gels containing the extract alone or with honey; both strains were sensitive to the studied concentrations (53).

The results of the present study showed no inhibition zones for the E. coli strain. Bernardo et al. evaluated the in vitro antimicrobial activity of an ethanolic extract of pomegranate and observed that it was effective against strains of Gram-positive and Gram-negative bacteria, including $E$. coli (54). The discrepancy between these results and ours could be explained by the different extraction techniques, solvents, and plant parts used to prepare the extracts. Different parts of the plant contain different constituents at varying concentrations (55), and one possible explanation for our results is that tested concentration of the pomegranate-peel extract was too low to prevent the growth of Gram-negative bacteria. Another factor that may explain the difference between the results is the type of bacterial strain used (56).

With regard to antifungal activity, growth inhibition of $C$. albicans was observed by the film containing the extract in the studied concentration, in accordance with numerous reports in the literature (57-59). Dantas de Almeida et al. investigated the MIC of pomegranate tinctures on C. albicans, C. krusei, and C. tropicalis, and reported values between 9 and $18.75 \mathrm{mg} . \mathrm{mL}^{-1}$ (57). Anibal et al. observed antifungal activity of the crude ethanolic extracts of the pericarp, seeds, and peels of pomegranate against strains of Candida $\operatorname{spp}(58)$. Lavaee et al. evaluated the antifungal activity of aqueous, ethanolic, and methanolic extracts of pomegranate-peel and root against strains of $C$. albicans and C. glabrata isolated from the human oral cavity (59). According to the data, methanol and ethanol extracts of the peel and roots inhibited both strains more effectively than the aqueous extracts. aureus isolados do leite de fêmeas bovinas (52). Os resultados encontrados mostraram maior atividade para o extrato das cascas do romã, porém, ambos foram considerados próprios para o uso pretendido. Zam et al. preparam um extrato aquoso a partir das cascas da romã que foi incorporado sozinho ou associado ao mel, em gel de goma de amido, na concentração de 2,5 a $10 \% \mathrm{p} / \mathrm{p}$. Os géis foram empregados para impregnar gazes a serem utilizadas sobre lesões. A suscetibilidade de linhagens de $P$. aeruginosa e $S$. aureus isoladas de feridas tratadas em hospital universitário foi avaliada frente aos géis e ambas as cepas se mostraram sensíveis às concentrações estudadas tanto do extrato puro quanto associado (53).

Resultados do presente trabalho mostram que não houve formação de zona de inibição para a cepa de $E$. coli. Bernardo et al. avaliaram a atividade antimicrobiana in vitro de um extrato etanólico de romã e observaram que o mesmo foi efetivo sobre cepas de bactérias Grampositivas e negativas, inclusive, sobre E. coli (54). A divergência deste resultado pode ser justificada em função das diferentes técnicas de extração empregadas na obtenção dos extratos, bem como dos solventes e das partes da planta utilizadas. Diferentes partes da planta contêm diferentes constituintes em diferentes concentrações (55), e uma possível explicação para nossos resultados é que a concentração testada do extrato de casca de romã foi muito baixa para prevenir o crescimento de bactérias Gram-negativas. Outro fator que pode explicar a diferença entre os resultados é o tipo de cepa bacteriana utilizada (56).

No que diz respeito à atividade antifúngica, foi observada inibição do crescimento de C. albicans pelo filme contendo o extrato na concentração estudada, em conformidade com inúmeros relatos da literatura (57-59). Dantas de Almeida et al. pesquisaram a CIM de tinturas de romã sobre $C$. albicans, $C$. krusei e $C$. tropicallis, e encontraram valores entre 9 e 18,75 $\mathrm{mg} . \mathrm{mL}^{-1}$ (57). Anibal et al. observaram atividade antifúngica de extratos etanólicos brutos preparados a partir do pericarpo, sementes e cascas de romã, frente a cepas de Candida spp (58). Lavaee et al. avaliaram a atividade antifúngica de extratos aquosos, etanólicos e metanólicos de casca e raiz de romã contra cepas de C. albicans e C. glabrata, isoladas de cavidades orais em humanos (59). De acordo com os dados obtidos, extratos de casca e raízes, obtidos com metanol e etanol, apresentaram efeito inibitório contra ambas as cepas e foram mais eficazes quando comparados aos aquosos. 


\section{Discussion}

Our present study offers new data on the use of electrospinning for the preparation of films containing crude pomegranate-peel extract for the use as a wound dressing. Numerous studies have described the effect of incorporating crude or standardized pomegranate extracts in different pharmaceutical formulations such as creams, lotions, gels, or ointments. However, there are few reports on the incorporation of crude or standardized pomegranate extracts in films for use as drug delivery. Amal et al. prepared films from a polymeric blend of starch, collagen, and chitosan, which were impregnated with an aqueous extract of the pomegranate pericarp. The extract was loaded into the finished film, but the maximum incorporated concentration was low (60). Hassanpour et al. prepared films containing standardized punicalagin, a secondary metabolite present in pomegranate extract, and reported that the films exhibited significant anti-inflammatory activity in wounds induced in rats (61). However, a disadvantage of punicalagin is the need to purify the crude pomegranate extract; this is different from our present study that used a crude pomegranate extract. The fractionation process requires organic solvents, is expensive, time-consuming, and greatly reduces the extract yield (59).

There are literature reports of electrospun films that include various bioactive compounds from medicinal plants. Sadri et al. produced films using Camellia sinensis (green tea) extract incorporated in polymeric chitosan and poly(ethylene oxide) (PEO) matrix produced by electrospinning (62). The susceptibility of $E$. coli and $S$. aureus strains to the films and their healing action as wound covers were subsequently evaluated. Results showed that the films containing green-tea extract inhibited the growth of both bacteria more effectively than films without the extract. The healing action of the extract-containing film was also demonstrated, and the authors attributed the improved tissue regeneration to the antimicrobial activity of the extract (62). Yousefi et al. prepared electrospun chitosan films containing extracts of Lawsonia inermis (henna) leaves and demonstrated significant synergistic antibacterial activity (63). The authors reported that combining chitosan and henna in the nanofibers promoted cell viability. Similar results were reported by Charernsriwilaiwat et al. who prepared electrospun films of chitosan containing ethylenediaminetetraacetic acid (EDTA) and Garcinia mangostana (mangosteen) extract (64). The films showed antimicrobial activity against Gram-positive and Gram-negative strains and

\section{Discussion}

Nosso presente estudo oferece novos dados sobre o uso da eletrofiação para a preparação de filmes contendo extrato bruto de casca de romã para uso como curativo. Um grande número de trabalhos descrevem os efeitos da incorporação de extratos de romã, brutos ou padronizados, em formas farmacêuticas diversas, como cremes, loções, géis ou pomadas. Contudo, são escassos os relatos sobre a incorporação em matrizes para a formação de filmes de uso como sistema de liberação. Amal et al. prepararam filmes a partir de uma mistura polimérica de amido, colágeno e quitosana, os quais impregnaram com um extrato aquoso do pericarpo de romã. Uma vez que o extrato foi incorporado no filme pronto, a concentração máxima passível de carregamento foi baixa (60). Hassanpour et al. prepararam filmes contendo punicalagina, um metabólito secundário presente no extrato de romã, e reportaram que os filmes tiveram capacidade anti-inflamatória significativa sobre feridas induzidas em ratos (61). No entanto, uma desvantagem do uso da punicalagina é a necessidade de purificação do extrato bruto de romã, diferente do que foi realizado no presente trabalho, que utilizou o extrato bruto. Processos de fracionamento requerem o uso de solventes orgânicos, são caros, demorados e promovem grande redução no rendimento do processo de extração (59).

Existem relatos na literatura de filmes eletrofiados baseados em compostos bioativos oriundos de outras plantas medicinais. Sadri et al. produziram filmes eletrofiados contendo extrato de Camellia sinensis (chá verde) incorporado em matriz polimérica de quitosana e poli(óxido de etileno) (PEO) (62). A suscetibilidade de cepas de $E$. coli e $S$. aureus frentes aos filmes foi avalaida, bem como sua capacidade cicatrizante. Os filmes contendo o extrato de chá verde quando comparados aos puros se mostraram eficazes na inibição do crescimento de ambas as bactérias estudadas. Os resultados mostraram que os filmes com extrato inibiram o crescimento microbiano mais efetivamente que os filmes sem extrato. A ação cicatrizante para o filme com extrato também foi comprovada e os autores atribuíram a regeneração tecidual aumentada à atividade antimicrobiana do extrato. Yousefi et al. prepararam filmes eletrofiados de quitosana contendo extrato de folhas de Lawsonia inermis (hena) e demosntraram a existência de atividade antimicrobiana sinérgica entre ambos (63). Segundo os autores, propriedades combinadas de nanofibras de quitosana e hena promoveram boa viabilidade celular. Resultados semelhantes foram observados por Charernsriwilaiwat 
enhanced healing. Ganesan and Paradeepa prepared electrospun PVA films containing an extract of Tridax procumbens (bull grass) and observed that it effectively inhibited strains of $S$. aureus and E. coli (65). MelendezRodriguez et al. prepared electrospun poly(3hydroxybutyrate-co-3-hydroxyvalerate) (PHBV) films containing eugenol essential oil, with antimicrobial activity, encapsulated in mesoporous silica nanoparticles at concentrations between 2.5 and $20 \% \mathrm{w} / \mathrm{w}$ for use as packaging (66). The authors observed that films without encapsulated eugenol were transparent but increasing the concentration of nanoparticles turned the films slightly yellow. Films with eugenol at concentrations above $10 \% \mathrm{w} / \mathrm{w}$ inhibited microbial growth. We have found no literature reports on the preparation and use of bioactive wound dressings in the form of electrospun films containing crude pomegranate-peel extract.

\section{Conclusions}

The pomegranate-peel extract obtained in hydrated ethylic alcohol was demonstrated to be nontoxic against fibroblast lineage and promoted cell proliferation, supporting its use as a possible wound-healing agent. Using electrospinning, we prepared a film containing a crude extract as a natural antimicrobial agent. We used a blend of PVA and sodium alginate at a 9:1 ratio as the matrix-forming agent. The film containing $1.25 \%$ $w / w$ of the extract showed a hemolysis index $<5 \%$, indicating good hemocompatibility. Strains of S. aureus and $S$. epidermidis bacteria and the fungus, C. albicans, but not $E$. coli were sensitive to the extract incorporated in the films. The results indicate that the films may be useful as a bioactive wound dressing. Preliminary assessments will be made in subsequent studies by treating wounds in laboratory animals using these experiments approved by the local ethics committee. et al., que prepararam filmes eletrofiados de quitosana contendo ácido etilenodiaminotetracético (EDTA) e extrato de Garcinia mangostana (mangostim) (64). Os filmes apresentaram atividade antimicrobiana sobre cepas Gram-positivas e Gram-negativas e atividade cicatrizante aumentada. Ganesan e Paradeepa eletrofiaram filmes de PVA contendo extrato de Tridax procumbensis (erva de touro) e observaram que os mesmos foram eficazes na inibição da proliferação de cepas de $S$. aureus e E. coli (65). MelendezRodriguez et al. preparam filmes eletrofiados de poli(3-hidroxibutirato-co-3-hidroxivalerato) (PHBV) contendo óleo essencial de eugenol encapsulado em nanopartículas de sílica mesoporosa em concentrações entre 2,5 e $20 \% \mathrm{p} / \mathrm{p}$, com vistas ao uso como embalagem ativa com atividade antimicrobiana (66). Os autores observaram que os filmes sem eugenol encapsulado se mostraram transparentes e que, com o aumento da concentração das nanopartículas, os filmes se tornaram amarelados. Filmes com eugenol em concentração superior a $10 \% \mathrm{p} / \mathrm{p}$ foram capazes de inibir o crescimento microbiano. Não encontramos nenhum relato na literatura sobre a preparação de coberturas bioativas na forma de filmes eletrofiados contendo extrato bruto de casca de romã.

\section{Conclusões}

O extrato da casca de romã obtido em etanol hidratado se mostrou não-tóxico para a linhagem de fibroblastos estudada e promoveu proliferação celular, o que justifica seu uso como possível agente cicatrizante. Empregando a técnica de eletroficação, preparamos um filme contendo um extrato bruto para uso como agente antimicrobiano natural. Usamos uma blenda de PVA e alginato de sódio, na proporção 9:1, como agente formador da matriz. O filme com o extrato a $1,25 \% \mathrm{p} / \mathrm{p}$ apresentou índice de hemólise $<$ que $5 \%$, indicando boa hemocompatibilidade. Cepas das bactérias $S$. aureus e $S$. epidermidis e do fungo C. albicans foram sensíveis à concentração de extrato incorporado nos filmes, ao contrário do observado para E. coli. Os resultados indicam que o filme pode ser potencialmente útil para uso como curativo bioativo. Avaliações preliminares da eficácia serão realizadas em animais de laboratório em estudos subsequentes, mediante aprovação do trabalho em comitê de ética local. 


\section{Authors' Contribution Statement}

The authors' contributions were as follows: SVB, SBS, TMS, KBA, FPC, MAPC and SOLS conducted the experiments. JAS prepared the extract. RLO, SFA, JAR and JCOV analyzed the results and wrote and corrected the manuscript.

\section{Acknowledgments}

The authors acknowledge the Fundação de Amparo à Pesquisa e Inovação do Espírito Santo (FAPES, Project 201/2019), the Fundo de Amparo à Pesquisa da Universidade Federal do Espírito Santo (UFES, FAP/ UFES/2015), and the Coordenação de Aperfeiçoamento de Pessoal de Nível Superior (CAPES, financing modality 001).

\section{Conflict of Interests}

The senior editor co-authoring this manuscript had no participation in the review nor in the decision process.

All authors have declared there were no financial and/ or personal relationships that may present a potential conflict of interest.

\section{Contribuições dos autores}

As contribuições dos autores foram as seguintes: SVB, SBS, TMS, KBA, FPC, MAPC, e SOLS realizaram todos os ensaios. JAS preparou e caracterizou o extrato. RLO, SFA, JAR and JCOV interpretaram os resultados, elaboraram e corrigiram o manuscrito.

\section{Agradecimentos}

Os autores agradecem à Fundação de Amparo à Pesquisa e Inovação do Espírito Santo - FAPES (TO\#201/2019; Edital 08/2018) pelo apoio financeiro, ao Conselho Nacional de Desenvolvimento Científico e Tecnológico - CNPQ, pela concessão de bolsas e, à Coordenação de Aperfeiçoamento de Pessoal de Nível Superior CAPES (modalidade de financiamento 001).

\section{Conflito de Interesses}

O editor senior envolvido na autoria deste manuscrito não teve qualquer participação no processo de revisão ou de decisão.

Todos os autores declararam não haver relações financeiras e/ou pessoais que possam representar um potencial conflito de interesses. 


\section{References / Referências}

1. Boateng J, Catanzano O. Advanced Therapeutic Dressings for Effective Wound Healing--A Review. J Pharm Sci. 2015; 104(11):3653-3680.

2. Sharma S, Dua A, Malik A. Third generation materials for wound dressings. IJPSR 2014; 5(6):2113-2124.

3. Dhivya S, Padma VV, Santhini E. Wound dressings - a review. Biomedicine, 2015; 5(4):24-28.

4. Boateng JS, Matthews KH, Stevens HN, Eccleston GM. Wound healing dressings and drug delivery systems: a review. J Pharm Sci. 2008; 97(8):2892-923.

5. Dutra JA, Carvalho SG, Zampirolli AC, Daltoé RD, Teixeira RM, Careta FP, Cotrim MA, Oréfice RL, Villanova JC. Papain wound dressings obtained from poly(vinyl alcohol)/calcium alginate blends as new pharmaceutical dosage form: Preparation and preliminary evaluation. Eur $\mathrm{J}$ Pharm Biopharm. 2017; 113:11-23.

6. Weller C, Sussman G. Wound dressings update. J Pharm Pract Res 2006; 36:318-324.

7. Zhao Y, Qiu Y, Wang H, Chen Y, Jin S, Chen S. Preparation of nanofibers with renewable polymers and their application in wound dressing. Int J Pol Sci, 2016(1):1-17.

8. Dias JL, Granja, PR, Bártolo, PJ. Advances in electrospun skin substitutes. Prog Mater Sci 2016; 84:314-334.

9. Bhardwaj N, Kundu SC. Electrospinning: a fascinating fiber fabrication technique. Biotechnol Adv. 2010; 28(3):325-47.

10. Memic A, Abudula T, Mohammed HS, Navare KJ, Colombani T, Bencherif AS. Latest progress in electrospun nanofibers for wound healing applications. App Bio Mat 2019; 2:952-969.

11. Souza SOL, Cotrim MAP, Oréfice RL, Carvalho SG, Dutra JAP, de Paula Careta F, Resende JA, Villanova JCO. Electrospun poly( $\varepsilon$-caprolactone) matrices containing silver sulfadiazine complexed with $\beta$-cyclodextrin as a new pharmaceutical dosage form to wound healing: preliminary physicochemical and biological evaluation. J Mater Sci Mater Med. 2018; 29(5):67-84.

12. Artem Ataide J, Caramori Cefali L, Machado Croisfelt F, Arruda Martins Shimojo A, Oliveira-Nascimento L, Gava Mazzola P. Natural actives for wound healing: A review. Phytother Res. 2018; 32(9):1664-1674

13. Calixto JB, Scheidt C, Otuki M, Santos AR. Biological activity of plant extracts: novel analgesic drugs. Expert Opin Emerg Drugs. 2001;6(2):261279.

14. Shedoeva A, Leavesley D, Upton Z, Fan C. Wound Healing and the Use of Medicinal Plants. Evid Based Complement Alternat Med. 2019;2019:2684108.

15. Araújo, M.A., Lemos, I. C. S., Demenezes, I. R. A., Fernandes, G. P., \& Kenrtopf, M. R. Uso de plantas medicinais para o tratamento de feridas. R Interd. 2015; 8(2):60-67.

16. Tsioutsiou EE, Giachetti D, Miraldi E, Governa P, Magnano AR,Biagi M. Phytotherapy and skin wound healing. Acta Vulnologica, 2016; 14(3):126-39.

17. Liakos I, Rizzello L, Hajiali H, Brunetti V , Carzino R, Pompa PP , Athanassiou A, Mele E . Fibrous wound dressings encapsulating essential oils as natural antimicrobial agents. J Mater Chem B. 2015; 3(8):1583-1589.

18. Güneş S, Tihmınlıŏglu F. Hypericum perforatum incorporated chitosan films as potential bioactive wound dressing material. Int J Biol Macromol. 2017; 102:933-943.

19. Lucas FDA, Kandrotas AL, Neto EN, Siqueira CED, André GS, Bromerschenkel I, Perri SHV. Copaiba oil in experimental wound healing in horses. Ciência Rural 2017; 47(04):1-7.

20. Pattanayak S, Dutta MK, Debnath PK, Bandyopadhyay SK, Saha B, Maity D. A study on ethno-medicinal use of some commonly available plants for wound healing and related activities in three southern districts of West Bengal, India. Exploratory Animal Med Res, 2012; 2(2):97-110.

21. Dutra FSG, Carlos LDA, Da Motta OV, Vianna AP, Pereira, SMF. Atividade antimicrobiana de extratos vegetais frente a bactérias de importância médica. Biológicas \& Saúde, 2016; 6(20):1-13.

22. Abdealsiede MMS, Alrasheid AA, Omar MMA, Elbashir AA. Antimicrobial and antioxidant activity of pomegranate-peel extracts obtained by sequential extraction method. Asian J Pharm Res Dev, 2020; 8(2):14-20.

23. Doostkam A, Iravani K, Bassiri-Jahromi. Punica granatum L. (pomegranate): a potential anti-microbial agent. Anti-infective Agents, 2020; $8(1): 2-14$

24. Jardini FA, Filho JM. Avaliação da atividade antioxidante em diferentes extratos da polpa e sementes da romã (Punica granatum L.). Rev Bras Cienc Farm. 2007; 43(1):137-147.

25. Pereira AV, Azevêdo TKB, Santana GM, Trevisan LFA, Higino SSS, Macêdo-Costa MR, Azevedo SS. Análise da atividade antimicrobiana de taninos totais de plantas aromáticas do Nordeste brasileiro. Agropecuária Técnica, 2015; 36(1):109-114.

26. Martins FWP, Casali AK. In vitro antimicrobial activity of ethanolic extracts of pomegranate (Punica granatum L.) on the bacteria Escherichia coli and Staphylococcus aureus. Braz J Devel, 2019; 5 (11):22970-22980.

27. Silva MA, Higino JS, Pereira JV, Siqueira-Júnior JP, Pereira MS. Antibiotic activity of the extract of Punica granatum Linn. over bovine strains of Staphylococcus aureus. Braz J. Pharmacogn. 2008; 18(2):209-212.

28. Lukiswanto BS, Miranti A, Sudjarwo SA, Primarizky H, Yuniarti WM. Evaluation of wound healing potential of pomegranate (Punica granatum) whole fruit extract on skin burn wound in rats (Rattus norvegicus). J Adv Vet Anim Res 2019; 6(2):202-207.

29. Costa NN, de Faria Lopes L, Ferreira DF, de Prado EML, Severi JA, Resende JA, de Paula Careta F, Ferreira MCP, Carreira LG, de Souza SOL, Cotrim MAP, Boeing T, de Andrade SF, Oréfice RL, Villanova JCO. Polymeric films containing pomegranate peel extract based on PVA/starch/ PAA blends for use as wound dressing: In vitro analysis and physicochemical evaluation. Mater Sci Eng C Mater Biol Appl. 2020;109:11064311702.

30. Chen FA, Wu AB, Chen CY. The influence of different treatments on the free radical scavenging activity of burdock and variations of its active components. Food Chem 2004; 86(4):479-484.

31. Vass P, Szabó E, Domokos A. Scale-up of electrospinning technology: applications in the pharmaceutical industry.WIREs Nanomed Nanobiotechnol. 2020; 12:e1611.

32. Wallin RF, Arscott EF. A practical guide to ISO 10993-5: cytotoxicity. Med Device Diag Ind, 1998; 20:96-98.

33. Baldovská S, Michalcová K, Halenár M, Carbonell-Barrachina AA, Kolesárová A. Polyphenol-rich pomegranate extract as a potential modulator of steroidogenesis in human ovarian cells. J Microbiol Biotech Food Sci, 2019; 8(6):1343-1346.

34. Packova D, Kolesárová A. Do punicalagins have possible impact on secretion of steroid hormones by porcine ovarian granulosa cells? J Microbiol Biotech Food Sci 2016; 5:57-59. 
35. Tan S, Huang X, Wu B. Some fascinating phenomena in electrospinning processes and applications of electrospun nanofibers. Polymer Int, 2007; 56(11):1330-1339.

36. Khan AR, Xiangyang S, Ahmad AMOX. Electrospinning of crude plant extracts for antibacterial and wound healing applications: a review. SM J Biomed Eng, 2018; 4(1):1024-1032.

37. Pilehvar-Soltanahmadi Y, Dadashpour M, Mohajeri A, Fattahi A, Sheervalilou R, Zarghami N. An Overview on Application of Natural Substances Incorporated with Electrospun Nanofibrous Scaffolds to Development of Innovative Wound Dressings. Mini Rev Med Chem. 2018;18(5):414427.

38. Silva JR, Sato TP, Borges ALS. Synthesis and morphological characterization of polycaprolactone (PCL) membranes with tara extract (Caesalpinia spinosa). Braz Dent Sc 2019; 22(2):163-170.

39. Yao CH, Yeh JY, Chen YS, Li MH, Huang CH. Wound-healing effect of electrospun gelatin nanofibres containing Centella asiatica extract in a rat model. J Tissue Eng Regen Med. 2017; 11(3):905-915.

40. Kamoun EA, Kenawy ERS, Chen X. A review on polymeric hydrogel membranes for wound dressing applications: PVA-based hydrogel dressings. J Adv Res. 2017; 8(3):217-233.

41. Pal K, Banthia K, Majumdar DK. Polymeric hydrogels: characterization and applications - a mini review. Des Monomers Polym. 2019; 12:197220.

42. Hayouni EA, Miled K, Boubaker S, Bellasfar Z, Abedrabba M, Iwaski H, Oku H, Matsui T, Limam F, Hamdi M. Hydroalcoholic extract basedointment from Punica granatum L. peels with enhanced in vivo healing potential on dermal wounds. Phytomedicine, 2011; 18(11):976-84.

43. Aslam MN, Lansky EP, Varani J. Pomegranate as a cosmeceutical source: pomegranate fractions promote proliferation and procollagen synthesis and inhibit matrix metalloproteinase-1 production in human skin cells. J Ethnopharmacol, 2006; 103(3):311-318.

44. Wang D, Özen C, Abu-Reidah IM, Chigurupati S, Patra JK, Horbanczuk JO, Jóźwik A, Tzvetkov NT, Uhrin P, Atanasov AG. Vasculoprotective effects of pomegranate (Punica granatum L.). Front Pharmacol. 2018; 9:544-59.

45. Fleck A, Cabral PF, Vieira FF. Punica granatum L. hydrogel for wound care treatment: from case study to phytomedicine standardization. Molecules, 2016; 21(8):1059.

46. Murthy KN, Reddy VK, Veigas JM, Murthy UD. Study on wound healing activity of Punica granatum peel. J Med Food. 2004 Summer;7(2):256-9.

47. Gullon B, Pintado ME, Pérez-Álvarez JA, Viuda-Martos M. Assessment of polyphenolic profile and antibacterial activity of pomegranate peel (Punica granatum) flour obtained from co-product of juice extraction. Food Control, 2016; 59:94-98.

48. Trindade MP, Fonseca L, Luiz PJL. Atividade antimicrobiana da tintura da casca de romã (Punica granatum) sobre cepas de Staphylococcus aureus e Streptococcus pyogenes: estudo in vitro. Revista Brasileira de Pesquisa em Saúde, 2009; 11(4):49-54.

49. Dahham SS, Ali MN, Tabassum H, Khan M. Studies on antibacterial and antifungal activity of pomegranate (Punica granatum L.). AmericanEurasian J. Agric. \& Environ. Sci. 2010; 9(3):273-81.

50. Abdollahzadeh SH, Mashouf RY, Mortazavi H, Moghaddam MH, Roozbahani N, Vahedi M. Antibacterial and antifungal activities of Punica granatum peel extracts against oral pathogens. J Dentistry, 2011; 8(1):1-6.

51. Machado TDB, Leal ICR, Amaral ACF, Santos KRND, Silva MGD, Kuster RM. Antimicrobial ellagitannin of Punica granatum fruits. J. Braz. Chem. Soc, 2002; 13(5):606-610.

52. Silva BT, Dos Anjos C, Fontes SM, Matsumoto LS, Peixoto ECTM, Silva LP, Silva RMG. Atividade antimicrobiana in vitro de extrato de Punica granatum L. sobre Staphylococcus aureus isolado em leite bovino. Bioscience J, 2013; 29(4):974-984.

53. Zam W, Harfouch R, Ali R., Atfah Y, Mousa A. Natural extracts and honey based impregnated gauze wound dressing preparation and in vitro antibacterial efficacy. Res. J. Pharmacognosy and Phytochem. 2018; 10(1):1-7.

54. Bernardo TH, Sales Santos Veríssimo RC, Alvino V, Silva Araujo MG, Evangelista Pires dos Santos RF, Maurício Viana MD, de Assis Bastos ML, Alexandre-Moreira MS, de Araújo-Júnior JX. Antimicrobial Analysis of an Antiseptic Made from Ethanol Crude Extracts of P. granatum and E. uniflora in Wistar Rats against Staphylococcus aureus and Staphylococcus epidermidis. ScientificWorldJournal. 2015; 2:751-791.

55. Carli, LE, Campos JR, Cota LOM. Efeitos terapêuticos do uso de produtos derivados da romã (Punica granatum) como coadjuvante no tratamento das doenças periodontais: uma revisão de literatura. Revista Periodontia, 2018; 28(2):32-42

56. Teles DG, Costa MM. Estudo da ação antimicrobiana conjunta de extratos aquosos de tansagem (Plantago major L., Plantaginaceae) e romã (Punica granatum L., Punicaceae) e interferência dos mesmos na ação da amoxicilina in vitro. Rev. Bras. Pl. Med. 2004 ; 16 (2) $323-328$.

57. Dantas De Almeida, L. D. F., Cavalcanti, Y. W., Júnior, R. L., Lima, E. D. O., \& Castro, R. D. D. Antifungal effect of tinctures from propolis and pomegranate against species of Candida. Rev Cubana Estomatol. 2012; 49(2):99-106.

58. Anibal PC, Peixoto ITA, Foglio MA, Hofling JF. Antifungal activity of the ethanolic extracts of Punica granatum L. and evaluation of the morphological and structural modifications of its compounds upon the cells of Candida spp. Braz J Microbiol 2013; 44(3):839-848.

59. Lavaee F, Motaghi D, Jassbi AR, Jafarian H, Ghasemi F, Badiee P. Efeito antifúngico dos extratos de casca e raiz de Punica granatum em isolados orais de Candida. Micologia Médica Atual. 2018; 4(4):20-24.

60. Amal B, Veena B, Jayachandran VP, Shilpa J. Preparation and characterisation of Punica granatum pericarp aqueous extract loaded chitosancollagen-starch membrane: role in wound healing process. J Mater Sci Mater Med. 2015; 26(5):181-190.

61. Hassanpour I, Tabatabaei NA, Aminlari M, Nazifi S. Effect of punicalagin nanofibrous-dressing on tissue total antioxidant capacity index through wound healing in adult Wistar rats. Zahedan J Res Med Sci. 2019; 21(2):e83932.

62. Sadri M, Arab-Sorkhi S, Vatani H, Bagheri-Pebdeni A. New wound dressing polymeric nanofiber containing green tea extract prepared by electrospinning method. Fibers Polym. 2015; 16(8):1742-1750.

63. Yousefi I, Pakravan M, Rahimi H, Bahador A, Farshadzadeh Z, Haririan I. An investigation of electrospun henna leaves extract-loaded chitosan based nanofibrous mats for skin tissue engineering. Mater Sci Eng C Mater Biol Appl, 2017; 75:433-444.

64. Charernsriwilaiwat N, Rojanarata T, Ngawhirunpat T, Sukma M, Opanasopit P. Electrospun chitosan-based nanofiber mats loaded with Garcinia mangostana extracts. Int J Pharm 2013; 452(1-2):333-343.

65. Ganesan P \& Pradeepa P. Electrospinning of PVA blended with Tridax Procumbens leaf extract. Chem. Fibers Int. 2017; 67:162-164.

66. Melendez-Rodriguez B, Figueroa-Lopez KJ, Bernardos A, Martínez-Máñez R, Cabedo L, Torres-Giner S, Lagaron JM. Electrospun antimicrobial films of poly(3-hydroxybutyrate-co-3-hydroxyvalerate) containing eugenol essential oil encapsulated in mesoporous silica nanoparticles. Nanomaterials 2019; 9(2):227-251. 